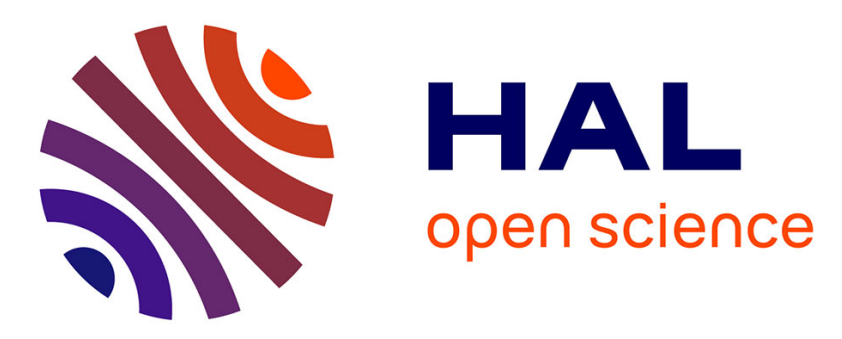

\title{
Spirobifluorene Dimers: Understanding How The Molecular Assemblies Drive The Electronic Properties
}

Cyril Poriel, Cassandre Quinton, Fabien Lucas, Joëlle Rault-Berthelot, Zuo-Quan Jiang, Olivier Jeannin

\section{- To cite this version:}

Cyril Poriel, Cassandre Quinton, Fabien Lucas, Joëlle Rault-Berthelot, Zuo-Quan Jiang, et al.. Spirobifluorene Dimers: Understanding How The Molecular Assemblies Drive The Electronic Properties. Advanced Functional Materials, 2021, 31 (43), pp.2104980. 10.1002/adfm.202104980 . hal-03331231

\author{
HAL Id: hal-03331231 \\ https://hal.science/hal-03331231
}

Submitted on 16 Sep 2021

HAL is a multi-disciplinary open access archive for the deposit and dissemination of scientific research documents, whether they are published or not. The documents may come from teaching and research institutions in France or abroad, or from public or private research centers.
L'archive ouverte pluridisciplinaire HAL, est destinée au dépôt et à la diffusion de documents scientifiques de niveau recherche, publiés ou non, émanant des établissements d'enseignement et de recherche français ou étrangers, des laboratoires publics ou privés. 


\section{Spirobifluorene Dimers. Understanding How The Molecular Assemblies Drive The Electronic Properties.}

Cyril Poriel, ${ }^{\mathrm{a}^{*}}$ Cassandre Quinton, ${ }^{\mathrm{a}}$ Fabien Lucas, ${ }^{\mathrm{a}}$ Joëlle Rault-Berthelot, ${ }^{\mathrm{a}}$ Zuo-Quan Jiang, ${ }^{\mathrm{b}}$ Olivier Jeannin ${ }^{\mathrm{a}}$

a. Univ Rennes, CNRS, ISCR-UMR 6226, F-35000 Rennes, France. E-mail: Cyril.poriel@univrennes1.fr.

b. Institute of Functional Nano \& Soft Materials (FUNSOM), Jiangsu Key Laboratory for Carbon-Based Functional Materials \& Devices, Soochow University, Suzhou, Jiangsu 215123, China.

TOC

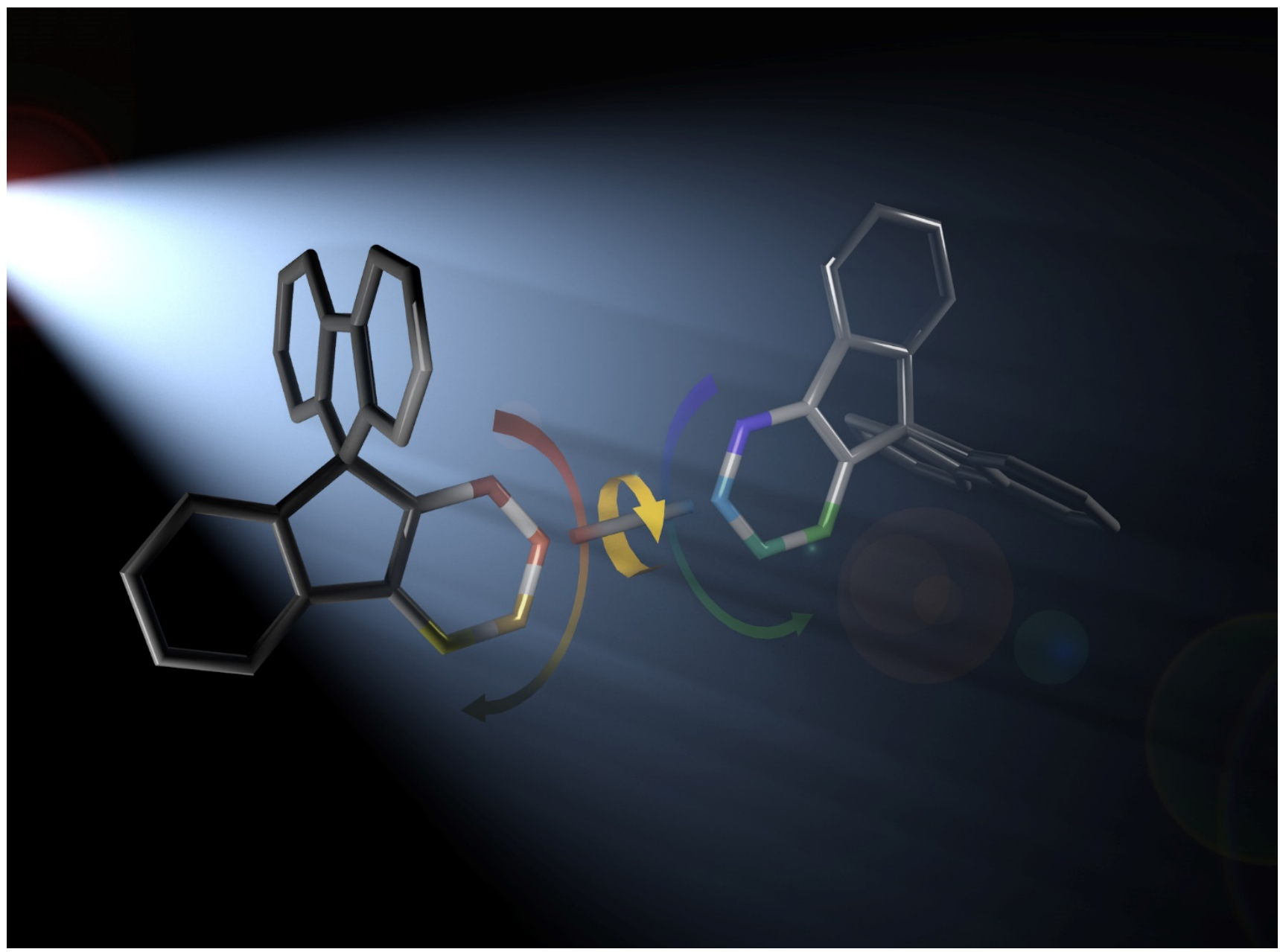

\section{Abstract}

The spirobifluorene (SBF) is one of the most important scaffold used in the design of Organic Semi-Conductors (OSCs) for electronics. In recent years, among all the structures developed for these applications, SBF dimers have been highlighted due to their great potentials in Thermally-Activated Delayed Fluorescence and in Phosphorescent Organic Light-Emitting Diodes. Attaching two SBF units generate 10 dimers, each possessing its own structural specificity, which in turn drives its electronic properties. These ten SBF dimers are gathered herein.Understanding how the molecular assembly determines the electronic properties has been one of the pillar of Organic Electronics. This is the 
goal of this article. As positional isomerism is a key tool to design OSCs, defining the design guidelines for the SBF scaffold appears of interest for the future of this building block. Herein, we discuss the importance of the two main parameters involved in the electrochemical and photophysical properties, namely the nature of the phenyl linkages involved and the steric congestion between the two SBF units. The combination of these two parameters drives the electronic properties but their respective weight is different as a function of the regioisomer involved or of the property considered (HOMO or LUMO energy level, absorption, fluorescence, phosphorescence). 


\section{Introduction}

The 9,9'-spirobifluorene (SBF) fragment ${ }^{[1][2]}$ is one of the most important scaffold used in the design of Organic Semi-Conductors (OSCs) for the emerging technologies of organic electronic. ${ }^{[3]}$ The origin of the success story of the SBF core is undoubtedly linked to its particular geometry and its consequences on the structural, physical and electronic properties. This fragment displays a singular geometry with two orthogonal fluorene backbones linked by a shared spiro carbon. Over the years, synthetic chemists have used the singular geometry of SBF to construct elaborated materials, playing around its 3D structure ${ }^{[4]}$ but also, more recently, around its substitution (Chart 1). ${ }^{[2,5]}$ The SBF platform offers indeed many different design options, which have evolved over the years. With two substituents on each fluorene, the tetra substitution has been far the most studied and has led to appealing cross-shaped structures used for example to generate porous networks (Chart 1, Top). Indeed, attaching various molecular fragments to the rigid perpendicular fluorene units allows generating privileged connecting directions for the design of open frameworks. This particularity has been advantageously used in molecular tectonics ${ }^{[6,7]}$ and metal organic frameworks (MOF) with different building units and metals. ${ }^{[8-10]}$ The tetracarboxylate SBF ligand $\mathbf{1}$ and its corresponding copper MOF is one example among others (Chart 1$).{ }^{[8]}$ The shape persistent macrocyclic nanocarbons (such as 2, chart 1 ) recently reported by Jasti and coworkers are also relevant examples of the high degree of complexity of tetrasubstituted SBF-based structures, which can be obtained in 2021 in the field of porous materials. ${ }^{[11]}$

Anchoring only one substituent on each fluorene allowsobtaining chiral materials with a very specific claw-like structure. Owing to the tetrahedral structure of the spiro carbon atom and perpendicular orientation of the two fluorenes, such a disubstituted SBF presents an axial chirality. ${ }^{[12]}$ In 1992, Diederich and co-worker have reported efficient enantiopure chiral receptors, which incorporate a cleft formed by a SBF unit functionalized with amidopyridine groups at the C2 and C2' position. ${ }^{[13]}$ The strong similitude between the claw-like structure of such di-substituted SBFs and that of 1,1'binaphtyl system was evidenced. ${ }^{[13]}$ Very recently, the chirality of the C2/C2'-substituted SBF scaffold has been used to construct new generations of spectacular chiral structures [n]spirobifluorenylenes 3 and $\mathbf{4}$ (Chart 1). ${ }^{[14]}$

However, in order to modulate the size of the cavity formed by the SBF scaffold and its chelate substituents, it was proposed to shift the substitution positions from C2 to C1. C1/C1'-disubstituted SBFs have thus appeared as efficient chiral ligands in asymmetric synthesis (see for example the structural arrangement of $\mathrm{PdCl}_{2}\left(\mathrm{SBF}\left(\mathrm{PPh}_{2}\right)_{2}\right) 5$ in Chart 1). ${ }^{[12,15]}$ These works have shown how the structural characteristics of the SBF core could be tuned by the substitution pattern, with strong consequences for the targeted applications, herein asymmetric catalysis. More recently, this design strategy using the positional isomerism of the SBF core has also been applied in materials science ${ }^{22]}$ and it is now a useful tool to modulate the electronic properties of SBF-based materials. ${ }^{[2,16,17]}$ Thus, fusing and/or bridging various molecular fragments on different positions of one, ${ }^{[18]}$ two ${ }^{[19]}$ or four fluorenes ${ }^{[20]}$ of the SBF core (such as in 6-9, chart 1 ) has allowed to obtain extended SBF-based OSCs with tunable molecular and/or supramolecular properties. 


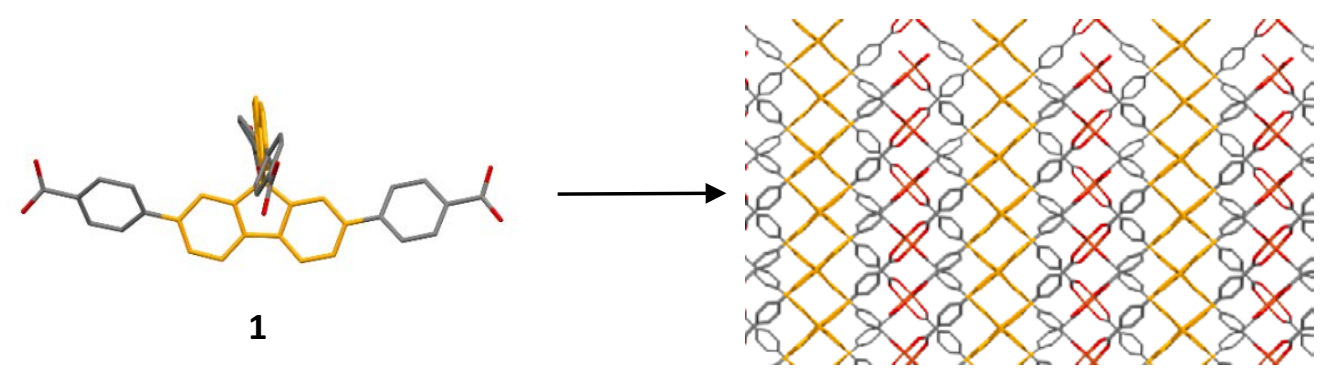

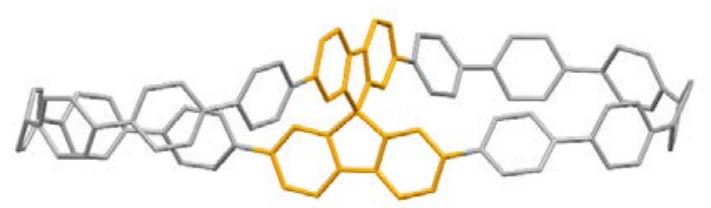

2

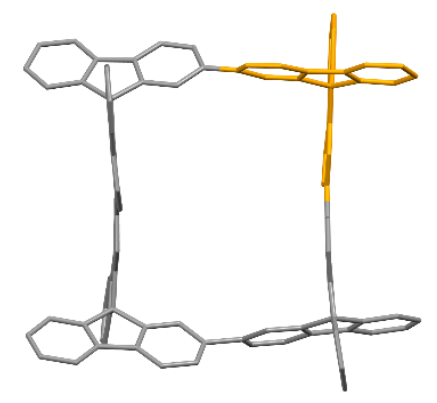

4

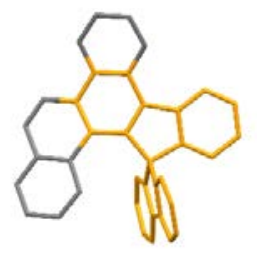

6

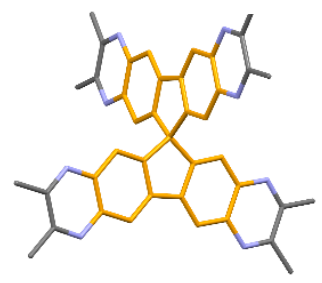

8

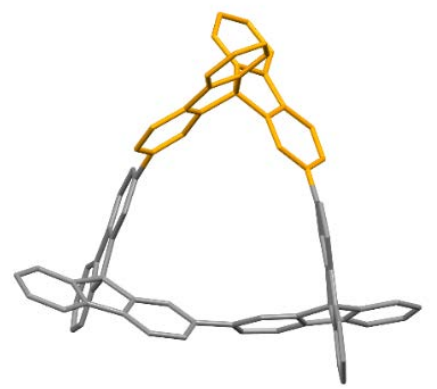

3

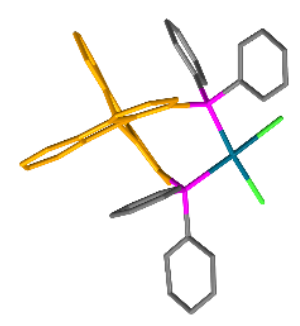

5

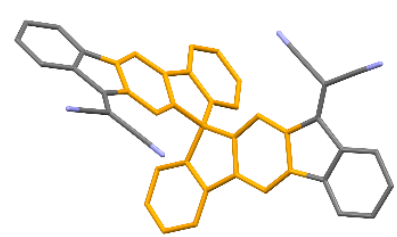

7

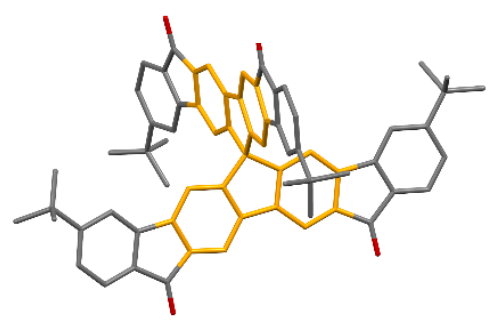

9

Chart 1. Examples of differently substituted SBF-based molecules. 4,4',4',4'"'-(9,9'spirobi[fluorene]2,2',7,7'-tetrayl)tetrabenzoic acid 1 and its Cu-based $\mathrm{MOF}^{[8]}$, spiro-Cycloparaphenylene $\mathbf{2}$ with 16 phenyl units (CCDC 1961179), ${ }^{[11]} \quad(\mathrm{S}, \mathrm{S}, \mathrm{S}, \mathrm{S})$-cyclo[3]spirobifluorenylene (CCDC 1991410) 3, ${ }^{[14]}$ (S,S,S,S)cyclo[4]spirobifluorenylene (CCDC 1991411) 4, ${ }^{[14]} \mathrm{PdCl}_{2}\left(\mathrm{SBF}\left(\mathrm{PPh}_{2}\right)_{2} \mathbf{5}\right.$ (CCDC 256882), ${ }^{13}$ spiro[fluorene9,15'-indeno[2,1-g]- chrysene] 6 (CCDC 1557124), ${ }^{[18]}$ spirobi[indeno[2,1-b]fluorene]-12,12'diylidene)dimalononitrile 7 (CCDC 1035932), ${ }^{[19]}$ 2,3,8,9,14,15,20,21-Octamethyl-tetrapyrazino[2,3-b:2',3'h:2",3"-b':2"',3"'-h']-9,9'-spirobifluorene $8 \quad$ (CCDC 15428680), ${ }^{[21]}$ 3,3',9,9'-Tetra-tert-butyl-6,6'spirobi[cyclopenta[2,1-b:3,4- b']difluorene]-12,12',15,15'-tetraone 9 (CCDC 1408336) ${ }^{[20]}$ 
However, the substitution pattern of the SBF core (positions of substitution C1, C2, C3 and/or C4) has been a design tool far less used than its 3D structure, most of the molecules reported in the last thirty years being substituted at $\mathrm{C} 2$, which are the electrophilic substitution positions of the fluorene unit. ${ }^{[4]}$ Attaching molecular fragments at $\mathrm{C} 1,{ }^{[16,22]} \mathrm{C} 3,{ }^{[16,23,24]}$ or $\mathrm{C} 4{ }^{[16,25,26]}$ nevertheless allow to strongly modulate both the electronic and structural characteristics and has opened new possibilities in term of materials design. Particularly, there has been a significant rise of these new generations of SBF isomers in the field of Phosphorescent Organic Light-Emitting Diodes (PhOLEDs) ${ }^{[16,24,26]}$ and Thermally Activated Delayed Fluorescence Organic Light-Emitting Diodes (TADF OLEDs). ${ }^{[27,28]}$ In recent years, among all the structures developed for these applications, SBF dimers have been particularly highlighted thanks to their great potentials in both TADF OLEDs ${ }^{[27]}$ and PhOLEDs. ${ }^{\text {[29] }}$ In this field of OSCs for electronics, oligomers are often constructed on the assembly of the same molecular unit and the dimeric structures are the simplest, which can be built. Perfectly understanding the properties of a $\pi$-conjugated dimer (for example $v$ s its monomer) has been a key step in the field of materials science to construct more complex structures (such as polymeric assemblies). In the case of the SBF fragment, ten different dimeric combinations can be generated, each possessing its own structural specificity, which in turn drives its electronic properties (Chart 2). These ten SBF dimers, are gathered for the first time in this work. Understanding how the molecular assembly determines the electronic properties has been one of the pillar of organic electronics (recently nicely discussed by Perepichka et al in the case of planarity ${ }^{[30]}$ ). This is the goal of this article. As positional isomerism is a more and more useful tool to design OSCs with specific properties, ${ }^{[16,31-35]}$ defining the design guidelines for the SBF scaffold appears of great interest for the future of this building block.

In this work, we discuss in detail the importance of the two main parameters involved in the electrochemical and photophysical properties of SBF dimers, namely the nature of the phenyl linkages (ortho, meta and para) and the steric congestion between the two SBF units. The combination of the two parameters drives all the electronic properties (and the corresponding devices' performance) but their respective weight is different as a function of the regioisomer involved and/or of the property considered (HOMO or LUMO energy level, absorption, fluorescence, phosphorescence). This is what we aim to discuss and unravel herein.

\section{Part 1. Presentation}

To date, eight dimers have been reported in the literature, ${ }^{[27,29,36-38]}$ and the last regioisomers in the series, 2,3"-(SBF)2 and 2,4"'-(SBF) 2 have been synthesized and studied for the purpose of this work (Chart 2). In this work, all the dimers have been synthesized and analysed in order to obtain full data sets in strictly identical experimental conditions, a key point to well analyse their fine differences. 


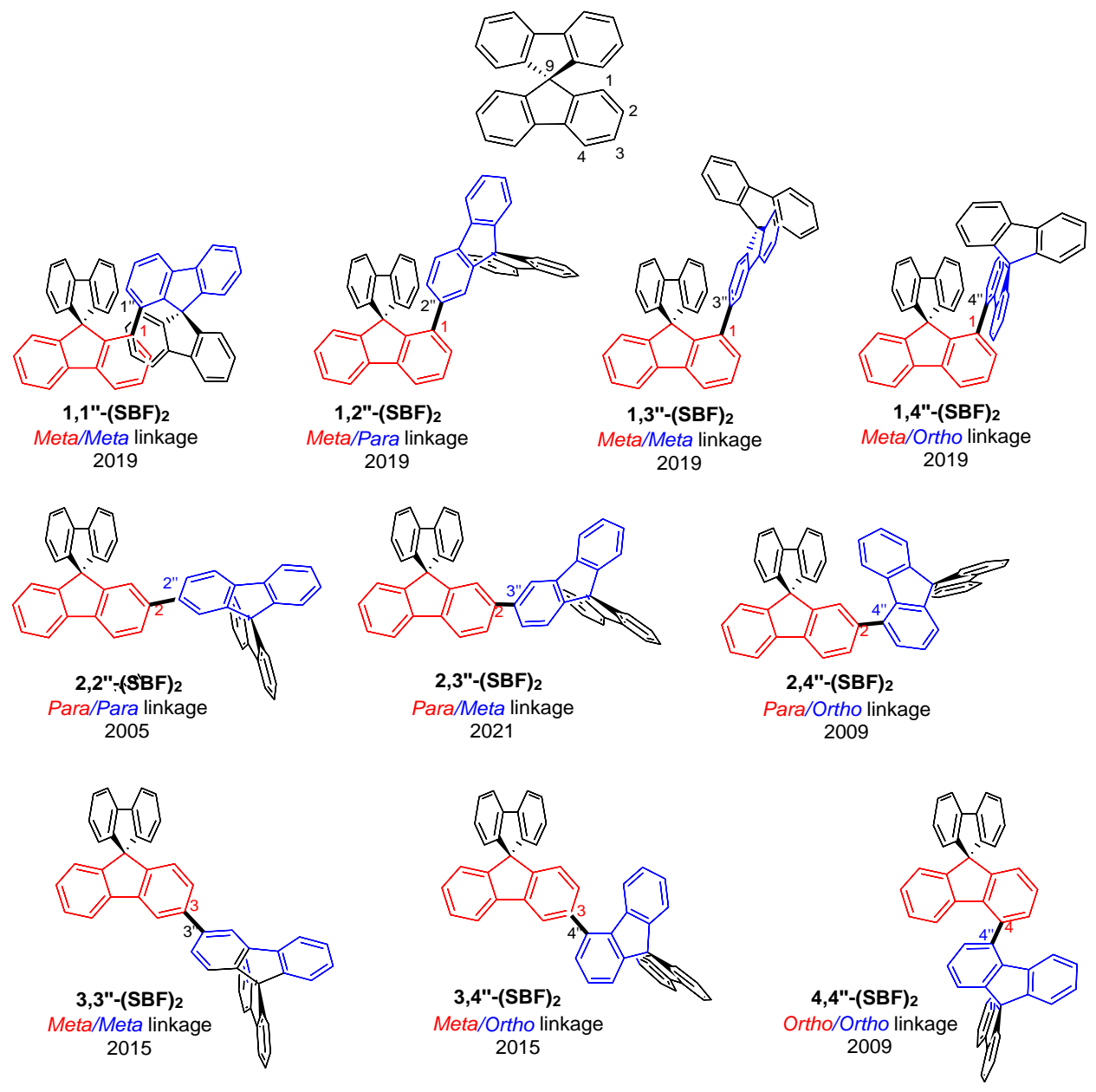

Chart 2. The ten SBF dimers (Nomenclature of SBF is also presented)

SBF compounds substituted at C2 have been the firsts to be developed because of synthetic considerations. A review has been reported by Salbeck and coworkers in 2007. ${ }^{[4]}$ SBFs monosubstituted at the three other positions C1, C3 and C4 were more difficult to synthesize and have only been reported in the last twelve years, respectively in $2017,{ }^{[16]} 2013^{[23]}$ and $2009 .{ }^{[38]}$ A recent feature article on these new generations of SBF positional isomers has been reported in 2019. ${ }^{[2]}$ In 2020, a review has shown the diversity of the molecular assemblies, which can be built from rigidly fused spiro-conjugated $\pi$-systems. ${ }^{[39]}$ All these reviews show the strong interest toward spiro based molecular architectures.

The first SBF dimer reported in literature, 2,2"'-(SBF)2, was published in 2005 and the substitution positions involved were logically the positions C2 (Chart 2). ${ }^{[36,37]}$ In 2017, its crystal structure was reported, highlighting a significant particularity (see below), ie the two fluorene units are surprisingly planar. ${ }^{[40]}$

In 2009, an important contribution dealing with the twisted C4-position of SBF was published. Thus, the strongly hindered 4,4''-(SBF)2 dimer (Chart 2) was synthesized and successfully incorporated in a green PhOLED as high-triplet $\left(\mathrm{E}_{\mathrm{T}}\right)$ host material. ${ }^{[38]}$ This work has open new avenues in the design of high $\mathrm{E}_{\mathrm{T}}$ host material for PhOLEDs.

In 2015, the first C3-linked SBF dimers, 3,3'-(SBF)2 and 3,4''-(SBF)2 (Chart 2), were reported showing, for the first time, the strong potential of pure hydrocarbon (PHC) derivatives as host in PhOLEDs. ${ }^{[27]}$ 
In 2019, the four C1-linked SBF dimers were reported (Chart 2), ${ }^{[29]}$ only two years after the first example of a C1-SBF derivative for electronics. ${ }^{[16]}$ When incorporated as host in PhOLEDs, these dimers have revealed extremely high efficiency (at that time, it was the highest performance reported in blue PhOLED for a PHC host). Thus, in less than two years, the C1-SBF scaffold has appeared as a powerful molecular backbone to design high $\mathrm{E}_{\mathrm{T}}$ host materials for electronics.

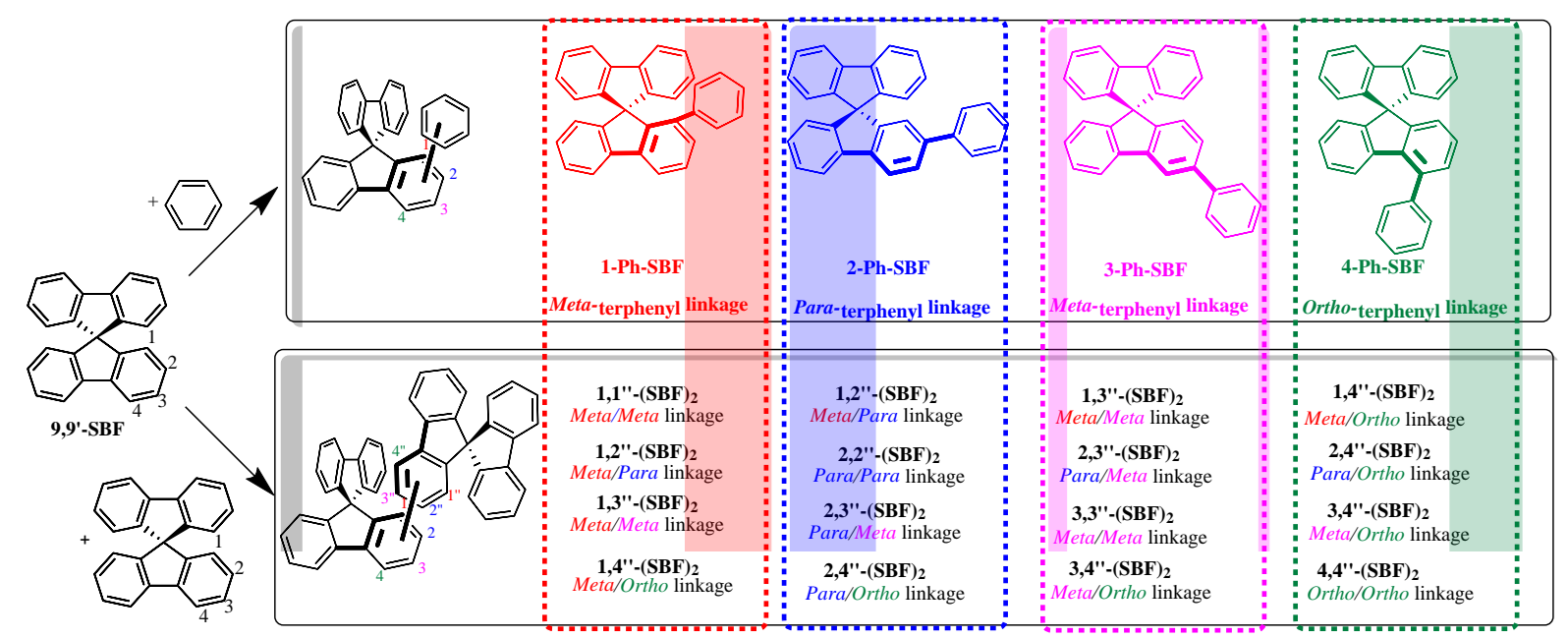

Figure 1. Nomenclature of the linkages in the SBF compounds considered in this work

To understand how the properties of these dimers can be modulated, one should first well visualize how these dimers are constructed and which parameters will be considered herein. Each molecule is constructed on the assembly of two SBF units, two fluorene backbones being linked and two others not. The coupling between the two linked fluorene units drives the electronic properties and depends on two parameters: the steric arrangement between the two SBF units and the nature of the central phenyl linkage (ortho, meta, para). Linking two fluorenes provides a central tetraphenyl fragment possessing different phenyl linkages as a function of its substitution (Figure 1). The four phenylsubstituted SBF regioisomers, presented in Figure 1, are relevant simplified model compounds to visualize the nature of the linkage. ${ }^{[16]}$ These four regioisomers display a terphenyl core (in bold in Figure 1) with a para linkage in the case of 2-Ph-SBF, a meta linkage in the case of 1-Ph-SBF and 3-Ph-SBF and an ortho linkage in the case of 4-Ph-SBF.

In the present case of the SBF dimers, the molecular assembly is more complicated as two fluorenes units are linked. Thus, each combination of the four SBF platforms (C1, C2, C3 and C4) provides a dimer, which can be described by the association of its linkages. Each association is presented in Figure 1. For example, the association of C1- and C2-SBF platform provides the 1,2'-(SBF)2 dimer with a tetraphenyl fragment displaying meta/para linkages. 


\section{Part 2. Structural Properties}

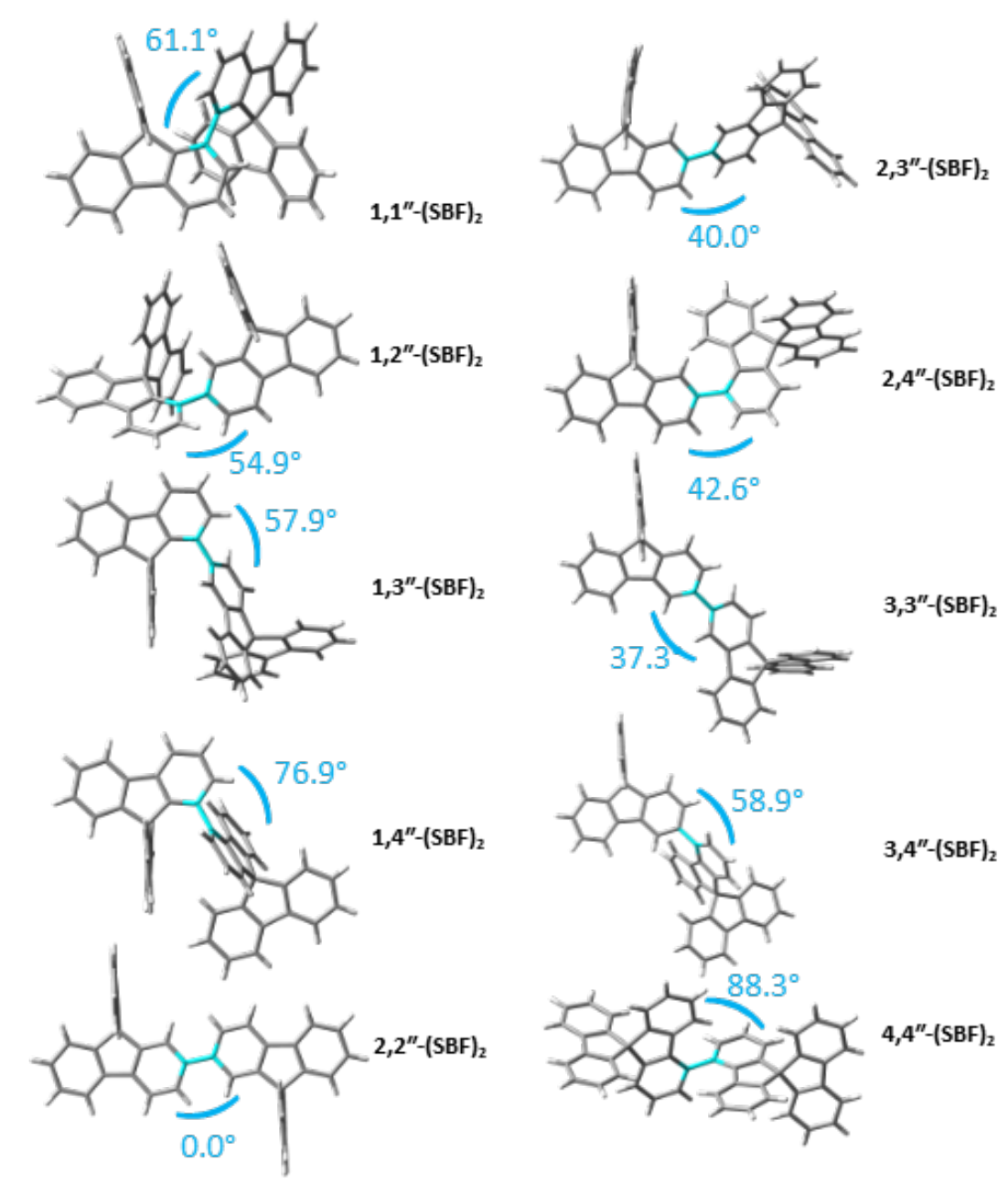

Figure 2. Evolution of the fluorene/fluorene dihedral angle in the ten SBF dimers (data obtained from X-Ray Crystallography)

Two parameters control the electronic properties (Table 1), which will be discussed in detail below: the electronic parameter (nature of the linkage, i.e. ortho, meta and para) and the steric parameter (relative position of the two SBF one to the other, i.e. fluorene/fluorene dihedral angle). First, let's have a look at the structural differences between the different isomers. Molecular structures at the solid-state have been resolved by X-Ray crystallography on single crystals and are presented in Figure 2. The main structural parameter is the fluorene/fluorene dihedral angle (measured as the angle between the planes of the two connecting phenyl units).

The lowest dihedral angle between the two fluorene units is recorded for $\mathbf{2 , 2}$ '"-(SBF) 2 as the two fluorenes appear to be perfectly coplanar. ${ }^{[40]}$ As theoretical calculations have shown that the planar conformation is not the optimal conformation in the ground state ${ }^{[41]}$ due to repulsive interactions between ortho-hydrogens of the bifluorene fragment, this result was, at a first attempt, surprising. Huang and coworkers have shown that $\pi-\pi$ stacking and $\mathrm{C}-\mathrm{H}-\pi$ interactions play a key role in the conformational planarization of 2,2'"-(SBF) $2 .{ }^{[40]}$ This dimer not only presents, in principle, the most conjugated central core (tetraphenyl with two para linkages) but also the lowest dihedral angle. This 
should strongly extend the conjugation pathway as shown below by UV-vis absorption spectroscopy (Figure 3).

Following the evolution of the dihedral angle as a function of the platforms used appears then informative. This angle remains below $40^{\circ}$ for two other dimers, namely 3,3''-(SBF)2 $\left(37.3^{\circ}\right)$ and 2,3'”-(SBF)2 $\left(40^{\circ}\right)$. Interestingly, 2,2''-(SBF)2, 2,3''-(SBF)2 and 3,3''-(SBF)2 are constructed with non-encumbered SBF platforms, substituted either at $\mathrm{C} 2$ and/or at C3. Changing the substitution to the position $\mathrm{C} 1$ or $\mathrm{C} 4$ drastically changes the deal. Indeed, the anchoring of the most relaxed C2-SBF platform to either C1- or C4-SBF increases the dihedral angle between the two fluorene units, from 2,4'-(SBF) $2\left(42.6^{\circ}\right)$ to 1,2''-(SBF) $2\left(54.9^{\circ}\right)$. In the light of above-mentioned data, the increase of the dihedral angle can only be assigned to the introduction of the sterically hindered C4- and C1-SBF platforms. This is confirmed with the other relaxed platform, i.e. C3-SBF. Indeed, the dihedral angle of $\mathbf{1 , 3} \mathbf{3}^{\prime \prime}-(\mathrm{SBF})_{2}\left(57.9^{\circ}\right)$ and $\mathbf{3 , 4}$ ''-(SBF) $2\left(58.9^{\circ}\right)$ is significantly increased when a C1-SBF or a C4SBF are respectively attached. This steric hindrance arises nevertheless from two different causes. For the C1-SBF platform, this is due to the presence of the cofacial spirofluorene unit. The strong interaction between the substituent at $\mathrm{C} 1$ and the cofacial fluorene interaction has been recently shown (and advantageously used in TADF OLEDs) ${ }^{[42,43]}$ for other C1-SBF based molecules. ${ }^{[22]}$ For the C4SBF platform, the steric hindrance is the geometric consequence of an ortho linkage. The combination of the two sterically hindered platforms, i.e. C1- and C4-, effectively provides SBF dimers with a

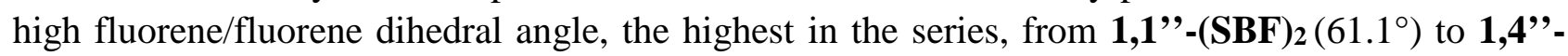
(SBF) $2\left(76.9^{\circ}\right)$ and to 4,4”'-(SBF)2 $\left(88.3^{\circ}\right)$.

Many information can be deduced from this set of data.

The C4-SBF platform provides the highest average dihedral angle. The ortho linkage of this platform leads to highly twisted molecules with strong steric congestion between the fluorenes. Linking two C4-SBF platforms leads to a dihedral angle close to $90^{\circ}$.

The C1-SBF platform also leads to high steric congestion. In these systems, we think there is a repulsion between the fluorene attached at $\mathrm{C} 1$ and the cofacial fluorene unit to minimize the $\pi-\pi$ interactions between the two sets of cofacial fluorenes. This is particularly visible for $\mathbf{1 , 1}$ '’ (SBF)2.

The two other platforms substituted at C2 or C3 do not provide any particular steric hindrance.

To conclude, two platforms lead to a small fluorene/fluorene angle (C2 and C3) and two others to a large one (C1 and $\mathrm{C} 4)$. This structural characteristic will be involved in the different electronic properties described below for all the dimers. With the $\mathrm{C} 1$ and $\mathrm{C} 4$ platforms, the steric parameter will have a key role. 


\section{Part 3. Optical Properties}

\section{Absorption}
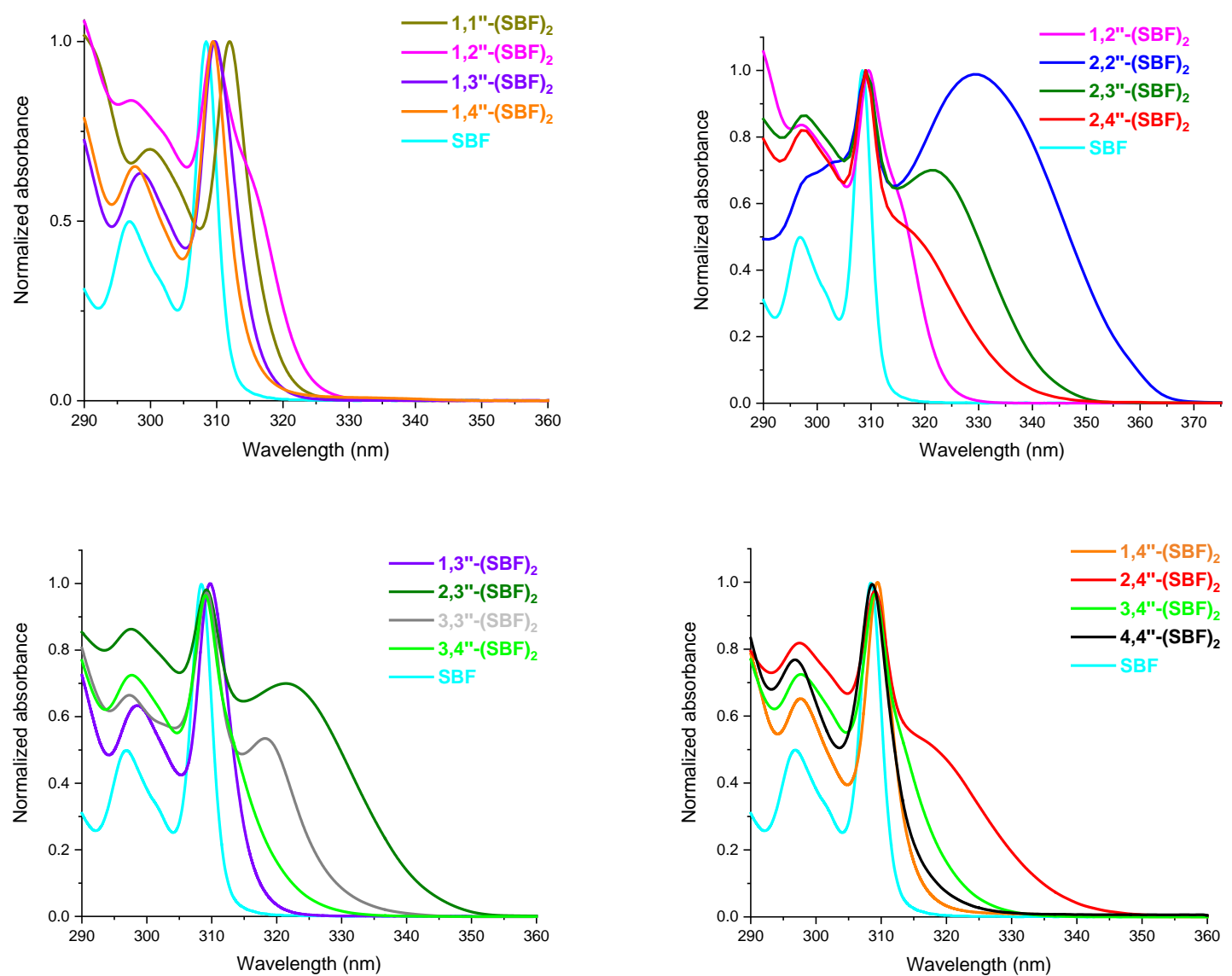

Figure 3. Absorption spectra (cyclohexane) of the ten dimers. Top. C1- series (Left), C2- series (Right). Bottom C3- series (Left), C4- series (Right). Absorption spectrum of SBF is added for comparison purpose

Figure 3 gathers the absorption spectra (cyclohexane) of four isomers in each series: C1-series (TopLeft), C2 (Top-Right), C3 (Bottom-Left) and C4 (Bottom-Right). This way of comparison allows to directly see the influence of the substitution pattern on a given platform.

First, it should be reminded that unsubstituted SBF exhibits two thin absorption bands at ca 297 and $308 \mathrm{~nm}(\pi-\pi *$ transitions). These two bands will also be found in all the dimers absorption spectra. Let's first consider the most common C2-SBF platform, which possesses a para linkage. In principle, the para linkage is the most efficient to induce a high electronic delocalization and a low dihedral fluorene/fluorene angle as exposed above. In addition to the two characteristic bands of SBF, 2,2'(SBF) 2 displays a very large and unresolved band with a maximum at $329 \mathrm{~nm}$. This band translates an extension of the $\pi$-conjugation from fluorene in SBF to fluorene-fluorene in 2,2' -(SBF)2 due to the combination of para linkage and a coplanar fluorene/fluorene system. By connecting a SBF unit at C3 in 2,3"'-(SBF)2, this band significantly decreases in intensity and is blue-shifted by ca $10 \mathrm{~nm}$. This feature has been assigned to a combination of two parameters: the meta vs para linkage and the increase of the dihedral angle between the two fluorenes. It is now admitted that despite a meta linkage is involved, ${ }^{[44,45]}$ the conjugation is nevertheless extended in such C3-substituted SBF systems. ${ }^{[2,16]}$ 
As the angle continues to increase in $\mathbf{2 , 4}$ '”-(SBF) 2 and in $\mathbf{1 , 2 "}-(\mathbf{S B F})_{2}$, the band at $329 \mathrm{~nm}$ dramatically decreases. It is nevertheless interesting to determine for these two isomers why there is a huge difference in the intensity of their respective tails. First, we can, of course, note that the fluorene/fluorene dihedral angle is higher in 1,2''-(SBF) 2 than in $\mathbf{2 , 4}$ ''-(SBF) $2\left(54.9\right.$ vs $\left.42.6^{\circ}\right)$ but this cannot fully explain the strong difference. In this case, the contribution of the linkage is also important. Indeed, an ortho linkage (C4) allows, from an electronic point of view, to extend the conjugation pathway but such linkage is often very twisted, ${ }^{[5,25,46-48]}$ restricting therefore the conjugation extension due to steric considerations. Oppositely, a meta linkage ${ }^{[45,49,50]}$ (C1) does not allow to efficiently extend the conjugation (despite a coupling exists between the fluorenes). The difference between 2,4'-(SBF)2 and 1,2'-(SBF)2 arises from this feature. In this series, the para linkage of the C2-SBF platform allows, even with the two sterically hindered C4 and C1-SBF platforms, to maintain a certain degree of conjugation between the two fluorenes. This will be different for the other C4 and C1-based dimers.

For the C3-SBF platform, the situation is similar and the conclusions drawn above are confirmed. Indeed, the band at $321 \mathrm{~nm}$ observed for 2,3'-(SBF)2 (translating the extension of the conjugation from a fluorene to a difluorene) is strongly diminished for 3,3'-(SBF)2, what can be essentially assigned to the switch from a para linkage for $\mathrm{C} 2$ to a meta linkage for $\mathrm{C} 3$ (electronic parameter), the fluorene/fluorene angle being almost identical for both molecules (40.0 vs $37.3^{\circ}$ respectively). As the dihedral angle increases in both 1,3'’-(SBF)2 and 3,4' -(SBF)2 (57.9 and 58.9 ${ }^{\circ}$ ), this band disappears for the former and appears as a tail for the latter. As observed above for the C2-compounds, the metalinked C1-SBF platform insures a more efficient $\pi$-conjugation breaking than the ortho-linked C4SBF one.

The two sterically hindered platforms, i.e. $\mathrm{C} 1$ and $\mathrm{C} 4$ follow the same rules. The four dimers constructed with the C4 platform, 1,4''-(SBF)2, 2,4'’-(SBF)2, 3,4'”-(SBF)2 and 4,4'-(SBF)2, display a huge fluorene/fluorene dihedral angle and corresponding absorption spectra are strongly impacted. In 2,4'-(SBF)2, the characteristic shoulder at ca $318 \mathrm{~nm}$, translating the fluorene/fluorene coupling is relatively intense and clearly detected. As detailed above, this extension of conjugation is enabled by the para linkage of the C2-SBF fragment, despite the two fluorene units are in this case relatively twisted $\left(42.6^{\circ}\right)$. When a C3-SBF is attached, in 3,4"'-(SBF)2, the shoulder at $318 \mathrm{~nm}$ is strongly diminished and appears as a tail. This behaviour, due to a combination of electronic (nature of the linkage: para vs meta) and steric (high dihedral angle) considerations is similar to that shown above with the $\mathrm{C} 2$ platform. This evidences that even with a sterically hindered platform, i.e. C4-SBF, the linkage effect is not completely erased (the impact of the steric hindrance and of the nature of the linkage on the HOMO/LUMO energy levels is described in the electrochemistry part). The same conclusion will be drawn with the C1-SBF platform but the effect will be strongly exacerbated. In the two other isomers, 1,4'-(SBF)2 and 4,4'-(SBF)2, there is no trace of such a low energy band. The spectra are very similar and also very similar to that of SBF. These spectra only differentiate by the width and the threshold of the band at $310 \mathrm{~nm}$, showing that the $\pi$-conjugation between the two SBF units is largely broken. This accords with the great dihedral angle measured for these dimers. One can note that the difference between $\mathbf{1 , 4}$ ''-(SBF)2 and 4,4''-(SBF)2, in term of threshold, is very small; the former with its meta linkage possessing nevertheless the lowest threshold meaning that the conjugation is almost completely broken.

Finally, the most blue-shifted spectra are obtained with the C1-SBF series. The four dimers substituted at C1, 1,1''-(SBF)2, 1,2'-(SBF)2, 1,3'-(SBF)2 and 1,4'-(SBF)2, all present the same overall structure with only the two clear characteristic bands of SBF at ca 297 and $310 \mathrm{~nm}$. Oppositely to all the other C2-substituted dimers presented above, 1,2''-(SBF) 2 only displays a small additional band at $316 \mathrm{~nm}$, overlapped with that at $310 \mathrm{~nm}$. This means that the association of a high steric hindrance $\left(54.9^{\circ}\right)$ and a meta linkage (found in C1) significantly erases the effect of the para linkage 
and the fluorene/fluorene electronic coupling is weak. The comparison of 1,2'-(SBF) 2 and 2,4'(SBF) 2 is particularly interesting. Indeed, in the latter, the extension of the conjugation is more intense than in the former. This clearly shows that the C1 platform (with a combination of a meta linkage and a high dihedral angle) more efficiently disrupts the conjugation than the C4 platform (ortho linkage). In the three other isomers, 1,1'-(SBF)2, 1,3'”-(SBF)2 and 1,4'”-(SBF)2, and as observed for their C4 analogues, the $\pi$-conjugation between the two SBF units is largely broken. Interestingly, a striking difference is nevertheless detected for 1,1”-(SBF)2. Indeed, its main band displays a $4 \mathrm{~nm}$ bathochromic shift in respect to its isomers and SBF. This feature has been assigned to the relatively strong tilt, which is undergone by the two unsubstituted fluorenes in order to minimize interaction with their cofacial substituted fluorenes, that alters the spiroconjugation. ${ }^{[51]}$ In all these dimers, the lowest threshold is measured for 1,4'’-(SBF)2.

\section{Fluorescence}

In emission spectroscopy (Figure 4), will be discussed the evolution of quantum yields, radiative and non-radiative constants (and related lifetimes), emission wavelengths, widths and shapes of the spectra. All these photophysical parameters can be related to the subtle differences in term of molecular structures. First, it should be reminded that the emission spectrum of SBF is thin, well structured and displays two maxima at 310 and $323 \mathrm{~nm}$ with a quantum yield (QY) of 0.55 (Figure 4, Table 1). All these characteristics are the consequence of a very rigid molecular structure with a very small Stokes shift, which translates similar geometries in the ground (S0) and the first excited (S1) states.
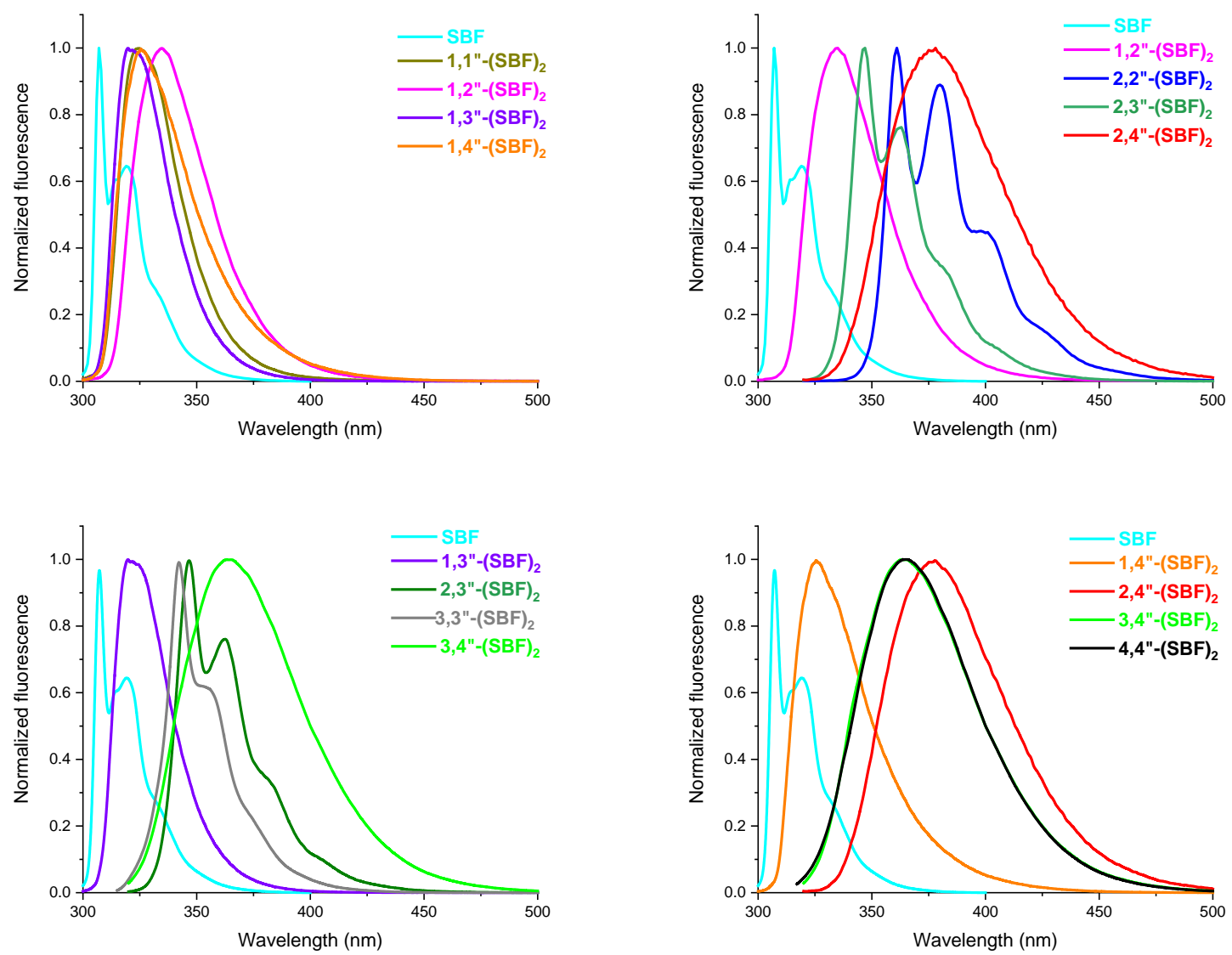

Figure 4. Emission spectra (cyclohexane) at room temperature of the ten dimers. Top. C1- series (Left), C2series (Right). Bottom C3- series (Left), C4-series (Right). SBF is added for comparison purpose 

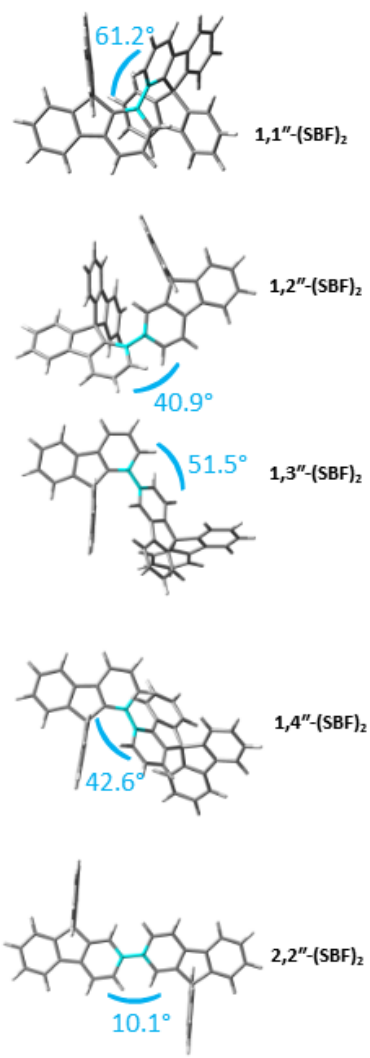
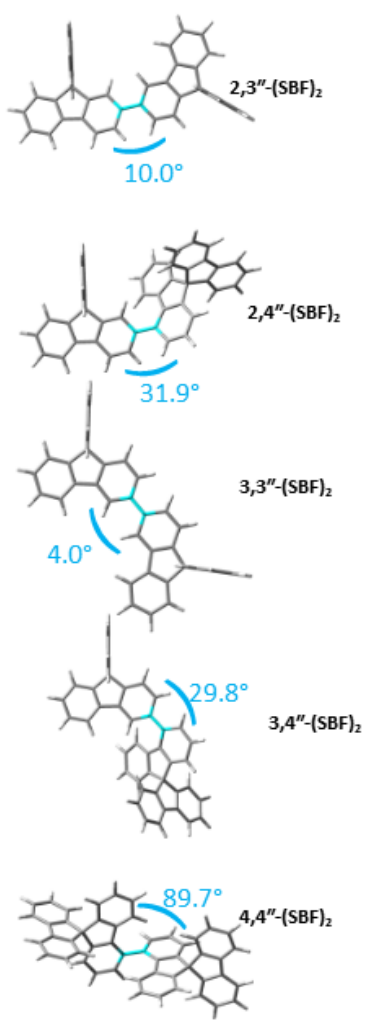
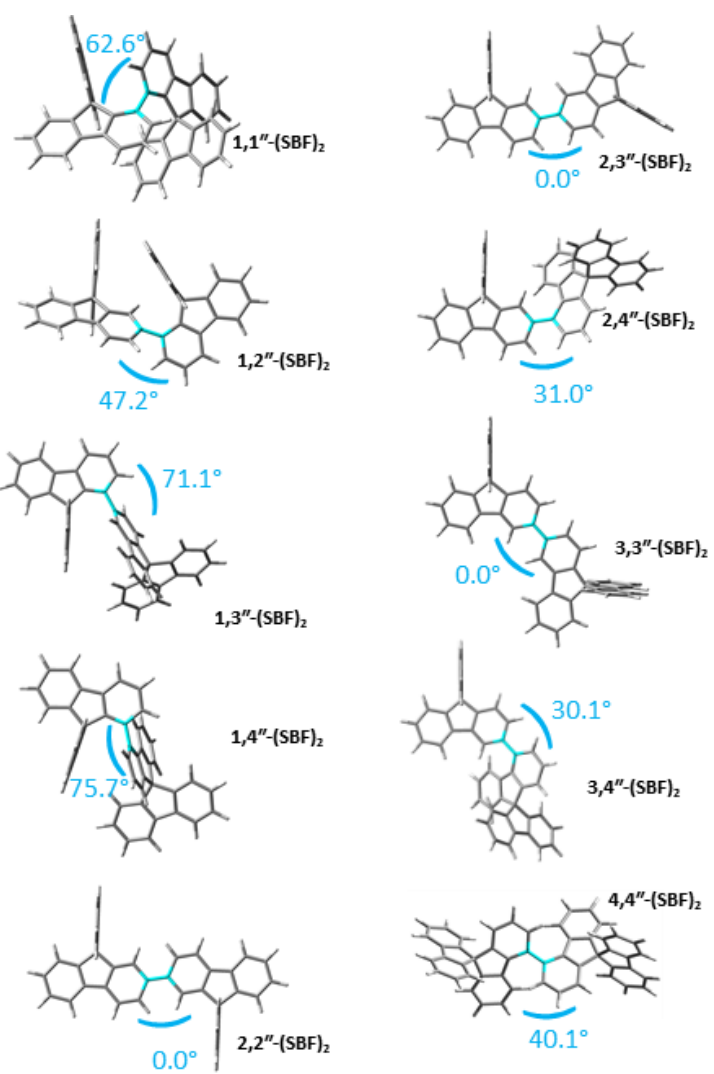

Figure 5. Optimized geometry of the first singlet excited state (S1, left, DFT b3lyp 6-31g(d)) and the first triplet state (T1, right, TD-DFT-b3lyp 6-311+g(d,p)) obtained by molecular modelling.

Let's first detail the C2-dimers series. 2,2"'-(SBF) 2 displays a classical fluorescence spectrum, thin, highly resolved, with three maxima at 360, 380 and $401 \mathrm{~nm}$. This emission is bathochromically shifted by $50 \mathrm{~nm}$ compared to that of $\mathbf{S B F}$, translating the extension of the conjugation. As often reported for many fluorophores and notably with fluorene- or SBF- based compounds, the spectrum is not the mirror image of its absorption spectrum, ${ }^{[52]}$ which is large and unresolved (Figure 4). This is due to the planarization of the system at the excited state, with a shortening of the sigma link, which displays a double bond character as shown by theoretical calculations, the dihedral angle between the two fluorenes in S1 state being equal to $10.1^{\circ}$ (Table 1, Figure 5, Left)

Attaching two SBF units by their C2 positions also significantly improves the QY compare to its building block SBF (0.99 vs 0.55, Table 1 ). This is the consequence of a strongly higher radiative constant $\mathrm{k}_{\mathrm{r}}\left(110\right.$ vs $12 \times 10^{7} \mathrm{~s}^{-1}$, Table 1$)$ due to the para connection. This will be found for all the other C2-based dimers discussed below.

The same behaviour is detected for 2,3'-(SBF)2, the three maxima being nevertheless blue shifted (347, 362 and $380 \mathrm{~nm})$. The QY and the $\mathrm{k}_{\mathrm{r}}$ are high $\left(0.89\right.$ and $65 \times 10^{7} \mathrm{~s}^{-1}$, Table 1$)$ but both lower than those of 2,2'-(SBF)2. These photophysical characteristics and the spectral blue shift are the consequence of the meta linkage of the C3-SBF platform. In addition, the fact that the spectrum is resolved translates a certain degree of liberty for the SBF units (compared to the other highly constrained SBF dimers described below). As for 2,2"'-(SBF), theoretical calculations have shown that the dihedral angle between the two fluorenes in $\mathrm{S} 1$ state is $10^{\circ}$, Figure 5, Left) with a shortening of the $\mathrm{C} / \mathrm{C}$ bond linking the two fluorenes (ca 1.49 vs $1.44 \AA$ ). This is also in accordance with the relatively large Stokes shift observed for these two dimers. Indeed, the Stokes shift dramatically decreases when the steric congestion increases as shown by 1,2'-(SBF)2. This characteristic will also be found for all the C1-dimers. Thus, the constrained structure of 1,2''-(SBF) 2 leads to an unresolved emission spectrum, which appears to be blue-shifted compared to 2,2"'-(SBF)2 and 2,3'”-(SBF)2. 
Therefore, the properties of $\mathbf{1 , 2}$ '”-(SBF) $\mathbf{2}$ become closer to those of SBF in term of Stokes shift (23 vs $2 \mathrm{~nm}$ resp) and maximum wavelength (335 vs 310 resp). Such a structureless emission spectrum is rare for SBF-based compounds and assigned to the congestion imposed to the sigma link hindering the planarization at the excited state, inducing a greater number of emitting conformers. As revealed by theoretical calculations (Figure 5, Left), the dihedral angle between the fluorenes is kept high in S1 $\left(40.9^{\circ}\right)$. This is one of the characteristics of the C1 series as shown below. The case of $\mathbf{2 , 4}$ '”-(SBF)2 is somewhat different as 4-substituted SBFs are known to display very particular fluorescence properties. ${ }^{5}$ This will not be deeply detailed herein but can be found in previous works. ${ }^{[5,25,26]}$ In $\mathbf{2 , 4}$ "'-(SBF) 2 , it is interesting to note that the dihedral angle in S1 is decreased compared to S0 $\left(42.6\right.$ vs $\left.31.9^{\circ}\right)$ but the planarization as found for $\mathbf{2 , 2}$ ''-(SBF)2 and $\mathbf{2 , 3}$ '”-(SBF) $)_{2}$ is not possible.

Thus, in the C2 series, the QY evolves as follows: 2,2"'-(SBF) $2(0.99)>\mathbf{2 , 3}$ ''-(SBF)2 $(0.89)>\mathbf{2 , 4}$ '”$(\mathbf{S B F})_{2}(0.80)$ and 1,2'-(SBF) 2 (0.77). Does this trend found for all the other dimers ? As discussed below, the C2 platform always provides the highest QY and is always followed by the C3 platform. The case of the two encumbered platforms C4 and C1 is different as it depends on the specific steric hindrance induced by these platforms.

The evolution of $k_{r}$ and $k_{n r}$ provides relevant information. The $k_{r} / k_{n r}$ decreases/increases from 2,2'"(SBF)2 to 2,3"'-(SBF)2 and to 2,4"'-(SBF)2 and 1,2"'-(SBF)2. Thus, increasing the steric hindrance with the C4 and C1 platforms tends to decrease $k_{\mathrm{r}}$ and increase $\mathrm{k}_{\mathrm{nr}}$ decreasing in turn the QY. Compared to SBF, the impact of the platform can be clearly highlighted. The relaxed dimers 2,2'”(SBF)2 and 2,3' '-(SBF) 2 display a higher $\mathrm{k}_{\mathrm{r}}$ and a lower $\mathrm{k}_{\mathrm{nr}}$, whereas encumbered dimers 2,4' '-(SBF)2 and 1,2''-(SBF)2 also display a higher $\mathrm{k}_{\mathrm{r}}$ but $\mathrm{k}_{\mathrm{nr}}$ is kept almost identical. This clearly shows how the platform influences the photophysics of the excited states.

From this series of dimers, the first conclusions can be drawn. One can conclude, that with relaxed structures, 2,2''-(SBF)2 and 2,3'”-(SBF)2, highly resolved fluorescence spectra are obtained, the QY is high, the emission is red-shifted compared to that of SBF and the Stokes shift is large. All these characteristics are the consequence of almost coplanar fluorene units in S1 state as shown by theoretical calculations (Figure 5). Despite a meta linkage is involved, the shape of the emission spectrum of 2,3''-(SBF) 2 is comparable to that of 2,2''-(SBF)2 and confirms that the C3-SBF scaffold allows an extension of the $\pi$-conjugation pathway. The two other isomers, 1,2"'-(SBF)2 and 2,4"'(SBF)2, with a more congested molecular system do not present a planar S1 state and therefore display unresolved spectra as their emissions arise from a great number of conformers. However, due to the para linkage, their QY remain nevertheless very high (0.77 and 0.80 respectively).

The next important question is to know if this trend is the same for all the dimers. The answer is yes.

3,3'-(SBF)2 does not present any steric congestion and displays all the characteristics above mentioned for relaxed structures, 2,2'-(SBF) 2 and 2,3'-(SBF)2. Thus, the spectrum is well resolved, with three maxima (342, 355 and $372 \mathrm{~nm}$ ) and the Stokes shift is large, in accordance with a planification of the linked fluorenes at S1 state (dihedral angle $=4.0^{\circ}$, Figure 5, Left). The influence of the linkages on the QY outlined above is confirmed with this example. Due to the meta/meta linkage, the QY of 3,3'-(SBF)2 (0.59) is significantly decreased compared to the two other relaxed dimers. This is mainly assigned to the decrease of $\mathrm{k}_{\mathrm{r}}$. This shows that dimers constructed on the C3 platform always present a lower QY compare to those constructed on the C2 platform (2,2'"-(SBF)2

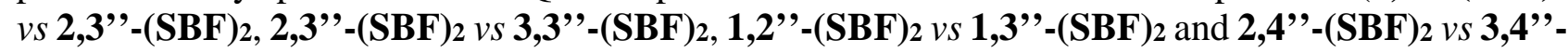
(SBF) 2) due to a combination of $\mathrm{k}_{\mathrm{r}}$ decrease and $\mathrm{k}_{\mathrm{nr}}$ increase. The meta linkage has therefore a significant impact on both radiative and non-radiative constants. Thus, in the C3 series, as shown for the C2 series, the relaxed dimers, 3,3'’-(SBF) 2 and 2,3'”-(SBF)2 display different characteristics 
(higher QY, higher $\mathrm{k}_{\mathrm{r}}$, well resolved spectra...) compared to the sterically hindered isomers 3,4'”(SBF)2 and 1,3'”-(SBF)2.

The C4 dimers display a peculiar fluorescence. The spectra are all large and unresolved and redshifted compared to all the other dimers. In S1 state, the four C4 based dimers all present twisted fluorene/fluorene backbone (dihedral angle comprised between 31.9 and $89.7^{\circ}$, Table 1). Interestingly, the $\mathrm{C} 4$ platform follows nevertheless the same rules than those exposed above. Thus, 2,4'-(SBF)2, with its para linkage displays the most red-shifted spectrum, whereas 1,4'-(SBF)2, with its combination of a meta linkage and a sterically hindered environment, the most blue-shifted. The trend in term of QY and $\mathrm{k}_{\mathrm{r}} / \mathrm{k}_{\mathrm{nr}}$ also appears to be the same, indicating a similar impact of the platform on the fluorescence properties. The relaxed dimers 2,4''-(SBF)2 and 3,4'"-(SBF)2 display a higher QY than the constrained dimers 1,4'-(SBF)2 and 4,4''-(SBF)2, Table 1. It is particularly interesting to correlate the QY decrease found in the following sequence 3,3"'-(SBF) $2-0.59>3,4$ '”(SBF) $2-0.51>4,4$ '"-(SBF) $2-0.33$ to visualize the influence of the C4 platform on this data. Adding one and then two C4-SBF platform gradually increases the $\mathrm{k}_{\mathrm{nr}}\left(10,19\right.$ and $24 \times 10^{7} \mathrm{~s}^{-1}$ respectively), which results in a QY decrease. The same trend is found for 2,2'"(SBF)2-0.99 > 2,4'"-(SBF)2-0.80 > 4,4'’-(SBF)2-0.33, confirming that a sterically hindered platform leads to a QY drop.

Finally, the data obtained with the $\mathrm{C} 1$ series have revealed a unique behaviour. The spectra of the four dimers 1,1"'-(SBF)2, 1,2' '-(SBF)2, 1,3”-(SBF)2 and 1,4'”-(SBF)2 are all unresolved, appear very close to that of SBF and span in a very short range of wavelengths (from 320 to $335 \mathrm{~nm}$ ). This is the only family of SBF dimers displaying such a behaviour. Such a structureless emission is rare for SBF derivatives and is the consequence of the $\mathrm{C} 1$ platform. In these structures, the steric hindrance strongly hinders the planarization at the excited state (the dihedral angles between the fluorenes are high: 61.2, 40.9, 51.5 and $42.6^{\circ}$ for 1,1''-(SBF)2, 1,2''-(SBF)2, 1,3”-(SBF) 2 and 1,4'-(SBF)2 respectively), inducing a greater number of emitting conformers. Except for $\mathbf{1 , 4}$ ''-(SBF)2, these angles are higher than those of their corresponding C4 counterparts. The four spectra remain in the near UV-violet region (despite two fluorenes are linked), which is an important point for their use as hosts in PhOLEDs as exposed below. The impact of the para linkage in 1,2"'-(SBF) 2 seems to be strongly diminished in this series. This will also be shown by the electrochemical data (see below). The spectra of 1,1'"-(SBF)2, 1,3"-(SBF)2 and 1,4' '-(SBF) 2 are nevertheless blue-shifted compared to that of 1,2"'-(SBF)2, translating the slight influence of the para linkage. From a spectral shape point of view, 1,1'-(SBF)2, 1,3'-(SBF) 2 and 1,4'-(SBF)2 are even difficult to discriminate with a similar maximum wavelength at 325, 320 and $326 \mathrm{~nm}$ resp. However, the three dimers present different QY, i.e. 0.25 for 1,1'"-(SBF)2, 0.47 for $\mathbf{1 , 3}$ ''-(SBF)2 and 0.37 for $\mathbf{1 , 4}$ ''-(SBF) 2 ) but similar lifetimes (Table 1). The low $\mathrm{k}_{\mathrm{r}}$ of $\mathbf{1 , 1} \mathbf{1}^{\prime}-(\mathrm{SBF})_{2}\left(5.4 \times 10^{7} \mathrm{~s}^{-1}\right)$, the lowest in the whole dimer series is at the origin of the QY loss compared to the two other dimers: $\mathrm{k}_{\mathrm{r}}=11 \times 10^{7} \mathrm{~s}^{-1}$ for $\mathbf{1 , 3} \mathbf{3}^{\prime}$-(SBF) 2 and $\mathrm{k}_{\mathrm{r}}=8.8 \times 10^{7} \mathrm{~s}^{-1}$ for 1,4'-(SBF)2. These $k_{r}$ values are nevertheless all significantly lower than that of 1,2''-(SBF)2, 39 $\times 10^{7} \mathrm{~s}^{-1}$, showing a stronger electronic transition moment in accordance with its higher QY (0.77). This is in accordance with the conclusion drawn above stating that high $\mathrm{k}_{\mathrm{r}}$ values are one of the characteristics of the C2 family (and leading to a high QY). Therefore, the effect of the C2 platform is herein reduced by the sterically hindered $\mathrm{C} 1$ platform.

It is important to mention to conclude this part, that except 2,2'”-(SBF)2, which possesses a low $\mathrm{k}_{\mathrm{nr}}$, of $1.1 \times 10^{7} \mathrm{~s}^{-1}$, the nine other dimers present $\mathrm{k}_{\mathrm{nr}}$ values similar to that of SBF ( $\mathrm{k}_{\mathrm{nr}}$ is between 7.3 and $24 \times 10^{7} \mathrm{~s}^{-1}$ for the dimers and $10 \times 10^{7} \mathrm{~s}^{-1}$ for SBF). Thus, despite their different structural environments, these dimers present similar vibrational deactivation pathways. The highest $k_{n r}$ is interestingly recorded for the dimer presenting the highest dihedral angle between the fluorenes, ie 4,4'’-(SBF). 


\section{Phosphorescence}
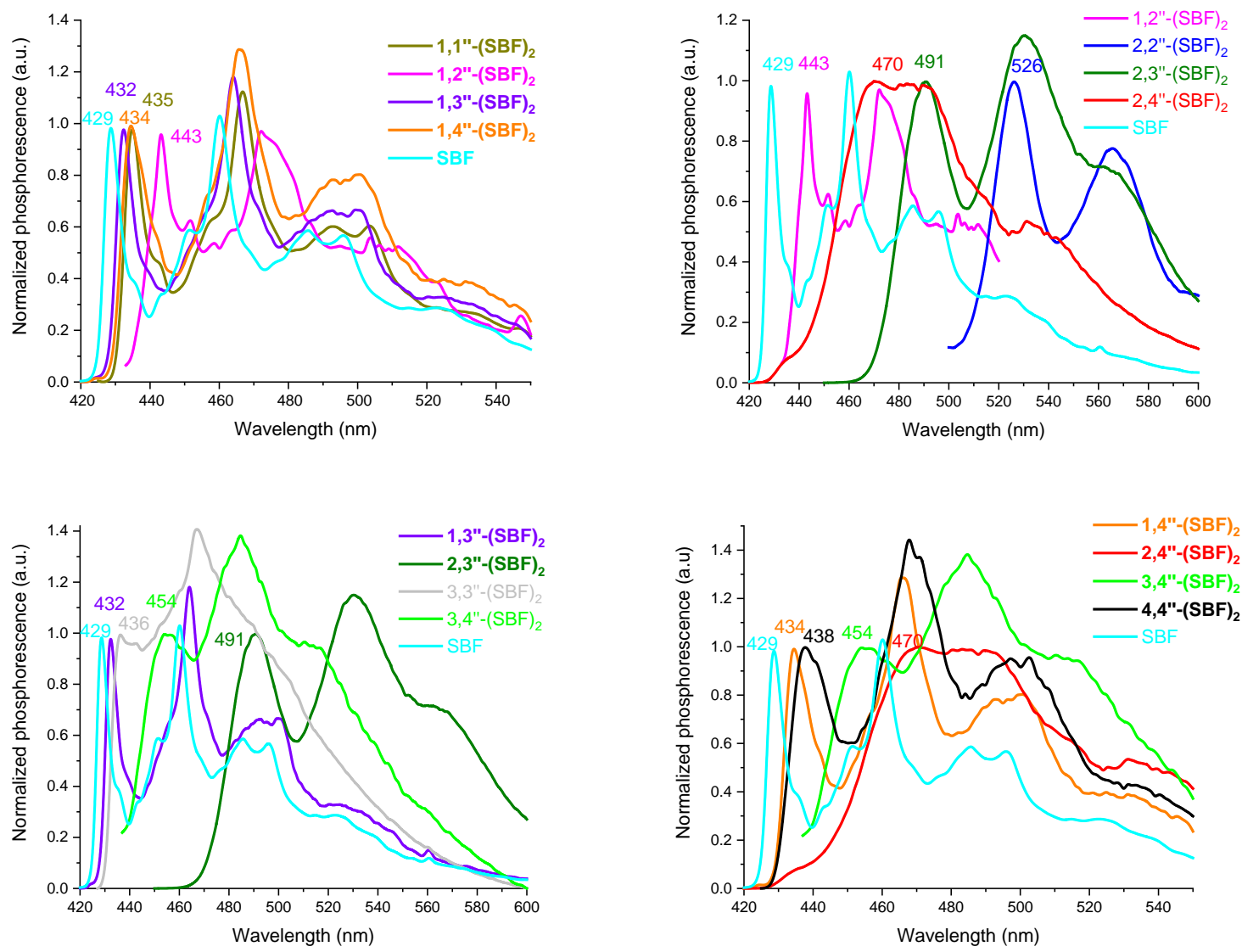

Figure 6. Emission spectra (cyclohexane) at $77 \mathrm{~K}$ of the ten dimers. Top. C1- series (Left), C2-series (Right). Bottom C3- series (Left), C4-series (Right). SBF is added for comparison purpose

The last question, that is important to answer is: How $T_{1}$ state energy level of the dimers is affected by the SBF positional isomerism?

We have shown above that the C1 scaffold is that which leads to the most efficient $\pi$-conjugation breaking. Thanks to this characteristic, the phosphorescence contribution (measured from the emission spectra at $77 \mathrm{~K}$ at the peak maximum, Figure 6) is strongly blue shifted compared to all the other isomers. The corresponding $\mathrm{E}_{\mathrm{T}}$ have been evaluated at ca 2.85, 2.80, 2.87 and $2.86 \mathrm{eV}$ for 1,1'"(SBF)2, 1,2"'-(SBF)2, 1,3''-(SBF)2 and 1,4'"-(SBF)2 respectively (Figure 6-Top, Left). The $\mathrm{E}_{\mathrm{T}}$ are all very high and close to that of $\mathbf{S B F}\left(\mathrm{E}_{\mathrm{T}}=2.89 \mathrm{eV}\right)$ as the triplet exciton is efficiently confined on one fluorene (Figure 7, Right). The highest $\mathrm{E}_{\mathrm{T}}$ is reported for $\mathbf{1 , 3}$ '”-(SBF) 2 due to the combination of two meta linkages and a constrained environment (dihedral angle in T1 state is measured at $71.1^{\circ}$, Table 1). The slightly lower value of $\mathbf{1 , 1}$ '-(SBF)2 could be assigned to the tilt of its unsubstituted fluorenes, altering the spiroconjugation, in accordance with the conclusion drawn from the UV-vis absorption spectra. The para isomer 1,2'-(SBF)2 displays a different behaviour as its triplet exciton is spread out on two fluorenes (Figure 7, Right), which decreases the $\mathrm{E}_{\mathrm{T}}$ to $2.80 \mathrm{eV}$. However, we should mention that this value is high for a 2-substituted SBF considering its para linkage. ${ }^{[5]}$ In 2019, these C1-SBF dimers have appeared as a real alternative to heteroatom-based host materials for blue 
PhOLEDs. ${ }^{[29]}$ In all the dimers series, the highest $E_{T}$ is found with the C1 scaffold (except for 1,1'(SBF)2 in the C1 series due to a spiroconjugation effect as shown above). Thus, in the C4-series, 1,4'-(SBF)2 presents a higher $E_{T}$ than that of the highly twisted 4,4''-(SBF) 2 (2.86 vs $2.83 \mathrm{eV}$ resp.). This is caused by the different electronic natures of the two linkages (ortho/ortho for 4,4'-(SBF)

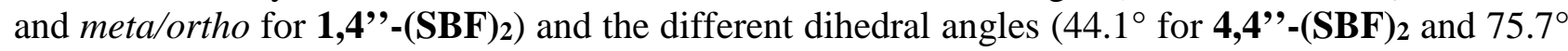
1,4''-(SBF)2). Then, the $\mathrm{E}_{\mathrm{T}}$ significantly drops down with the two non-encumbered platforms, i.e. C3 and C2. Thus, 3,4''-(SBF)2 and 2,4'-(SBF)2 display an $\mathrm{E}_{\mathrm{T}}$ of 2.73 and $2.64 \mathrm{eV}$ resp in accordance with a triplet exciton spread out on the two connected fluorenes (Figure 7, Right). As the fluorene/fluorene dihedral angle in $\mathrm{T} 1$ is almost identical (ca $30^{\circ}$ ), the difference arises from the nature of the linkage (meta vs ortho). However, as the $\mathrm{E}_{\mathrm{T}}$ of $\mathbf{3 , 4}$ '"-(SBF) 2 is kept lower than that of 4,4''-(SBF)2 (2.73 vs $2.83 \mathrm{eV}$ ), this shows also the importance of the dihedral angle on the $\mathrm{E}_{\mathrm{T}}$ value. Thus, these data show how the relative weight of the steric hindrance and the linkage on the $\mathrm{E}_{\mathrm{T}}$ values is not easy to determine. The three dimers, which do not present any steric hindrance, 2,2'-(SBF)2, 2,3'-(SBF $)_{2}$ and 3,3'”-(SBF $)_{2}$ respectively display an $\mathrm{E}_{\mathrm{T}}$ lying at 2.36, 2.53 and $2.84 \mathrm{eV}$. If the very low $\mathrm{E}_{\mathrm{T}}$ of the two first were obvious due to the efficient $\pi$-electronic delocalization induced by the para linkage, the case of $\mathbf{3 , 3}$ ',-(SBF) 2 is more surprising. Indeed, we have shown above that the meta linkage in this molecule does not fully block the $\pi$-conjugation between the two fluorenes. Thus, despite the two fluorene units are coplanar in $\mathrm{T} 1$ (dihedral angle $=0^{\circ}$ ), the $\mathrm{E}_{\mathrm{T}}$ of $\mathbf{3 , 3}$ '”-(SBF) 2 is kept very high. The triplet exciton in these three molecules is differently spread out on the two connected fluorenes and follows the experimental trend (Figure 7, Right). For 2,2''-(SBF)2, the triplet exciton is spread out on the four phenyl units of the two connected fluorenes but for 3,3'-(SBF)2, the triplet exciton is concentrated on the central biphenyl fragment in accordance with its high $\mathrm{E}_{\mathrm{T}}$ value. Such a triplet localization is unique in the dimer series and a particularity of the C3 platform.

Thus, the $\mathrm{E}_{\mathrm{T}}$ of 3,3'"-(SBF) 2 is higher than that of 3,4''-(SBF) $)_{2}$ showing that the linkage has a stronger influence on the $\mathrm{E}_{\mathrm{T}}$ than the dihedral angle (Figure 5, Right). The localization of the triplet exciton, biphenyl for the former and ortho-terphenyl for the latter is in accordance with the experimental data. The same analysis can be done for 3,3"'-(SBF) 2 and 1,3'-(SBF)2 (both meta/meta linkage) which possess a very similar $\mathrm{E}_{\mathrm{T}}$ despite a very different dihedral angle. However, the influence of the dihedral angle and the linkage is also dependent of the positional isomer involved. Indeed, despite its meta linkage, 2,3'”-(SBF)2 displays a lower $\mathrm{E}_{\mathrm{T}}$ than 2,4'-(SBF)2, therefore assigned to angular considerations. In 2,3'-(SBF)2, the two fluorene units are coplanar in T1 state and the para linkage significantly decreases the $\mathrm{E}_{\mathrm{T}}$ value, whereas in $\mathbf{2 , 4}$ '"-(SBF) $)_{2}$, the dihedral angle is measured at $31^{\circ}$, keeping a relatively high $\mathrm{E}_{\mathrm{T}}$ value. This shows how, as a function of the positional isomer involved (and hence the nature of its linkage), the dihedral angle holds a different importance in the $\mathrm{E}_{\mathrm{T}}$ value.

The conclusion of this part is that both steric hindrance and nature of the linkage are key parameters in the $\mathrm{E}_{\mathrm{T}}$ values. As a function of the isomer involved, these parameters have different weights. In each series, the position C2, due to its para linkage, always leads to the lowest $\mathrm{E}_{\mathrm{T}}$ even with highly sterically hindered platforms. With the C3 platform, due to its meta linkages, high $\mathrm{E}_{\mathrm{T}}$ are always reached even with relaxed dimers. The comparative analysis of all the dimers constructed on the $\mathrm{C} 4$

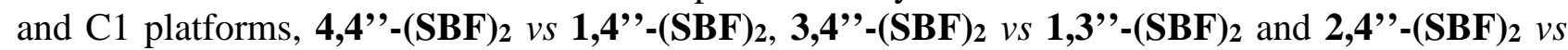
1,2''-(SBF)2 allows concluding that the highest $\mathrm{E}_{\mathrm{T}}$ values are always obtained with the C1 scaffold, independently of the linkage involved (only the couple $\mathbf{1 , 4}$ '"-(SBF) $2 / \mathbf{1 , 1}$ ''-(SBF)2 is different due to spiroconjugation considerations). Gathering a high steric hindrance and a meta linkage, as in 1,3'(SBF) 2 is therefore the most efficient combination to reach a high $\mathrm{E}_{\mathrm{T}}(2.87 \mathrm{eV})$, which is almost identical to that of building unit SBF. 
$1,1^{\prime \prime}-(\mathrm{SBF})_{2}$
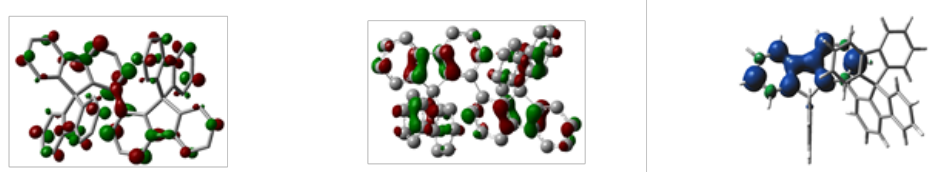

$1,2^{\prime \prime}-(\mathrm{SBF})_{2}$
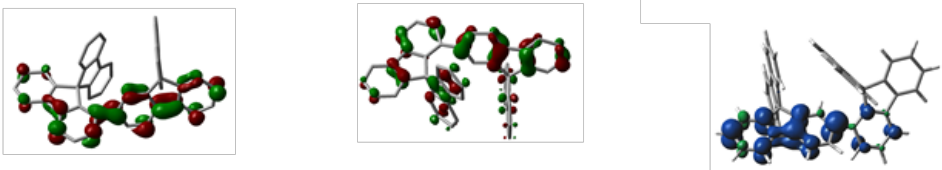

$1,3^{\prime \prime}-(\mathrm{SBF})_{2}$
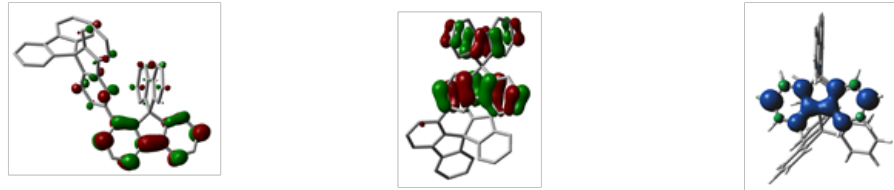

$1,4^{\prime \prime}-(\mathrm{SBF})_{2}$
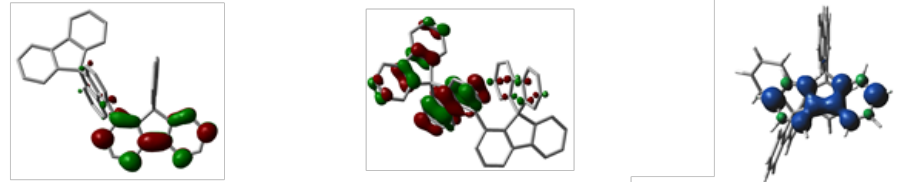

2,2 "'-(SBF) 2
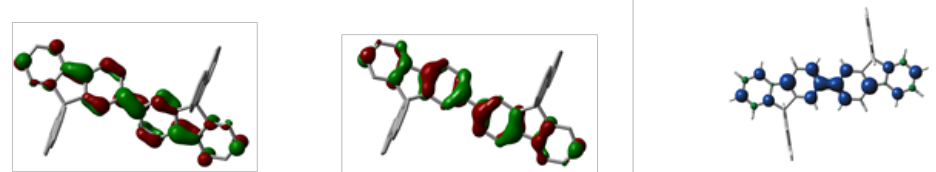

$2,3^{\prime \prime}-(\mathrm{SBF})_{2}$
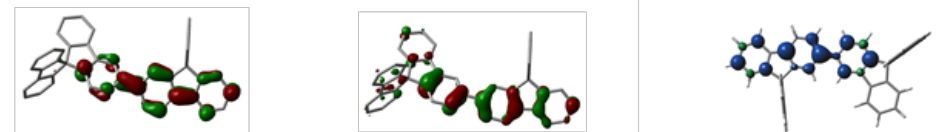

$2,4^{\prime \prime}-(\mathrm{SBF})_{2}$
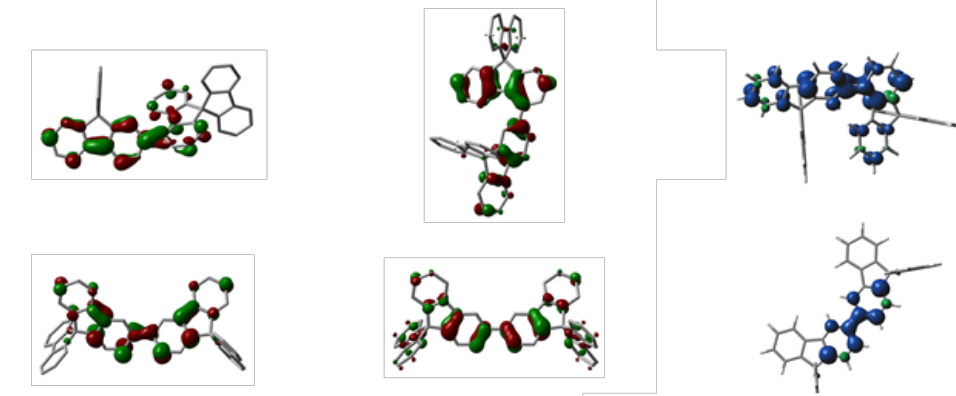

$3,4^{\prime \prime}-(\mathrm{SBF})_{2}$
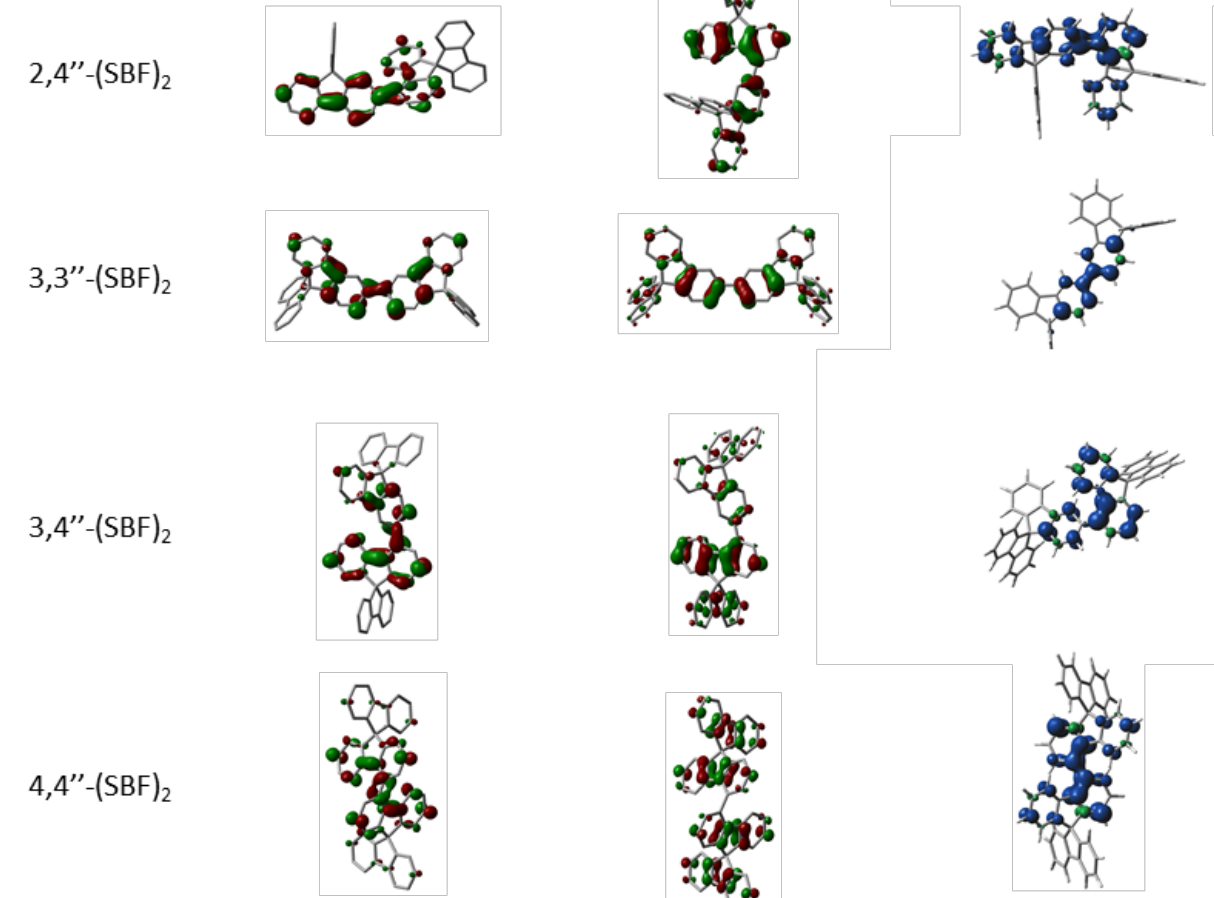

$3,3^{\prime \prime}-(\mathrm{SBF})_{2}$
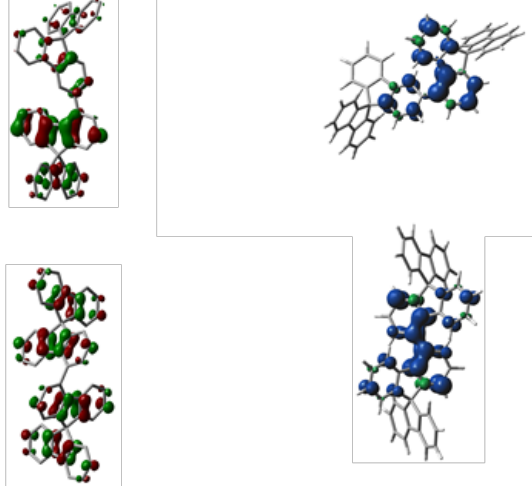

Figure 7. Frontier molecular orbitals (left: LUMO, middle: HOMO) and Spin Density Distribution (SDD) triplet (right) with isovalues of 0.04 and 0.004 respectively (b3lyp/6-311+g(d,p)) 

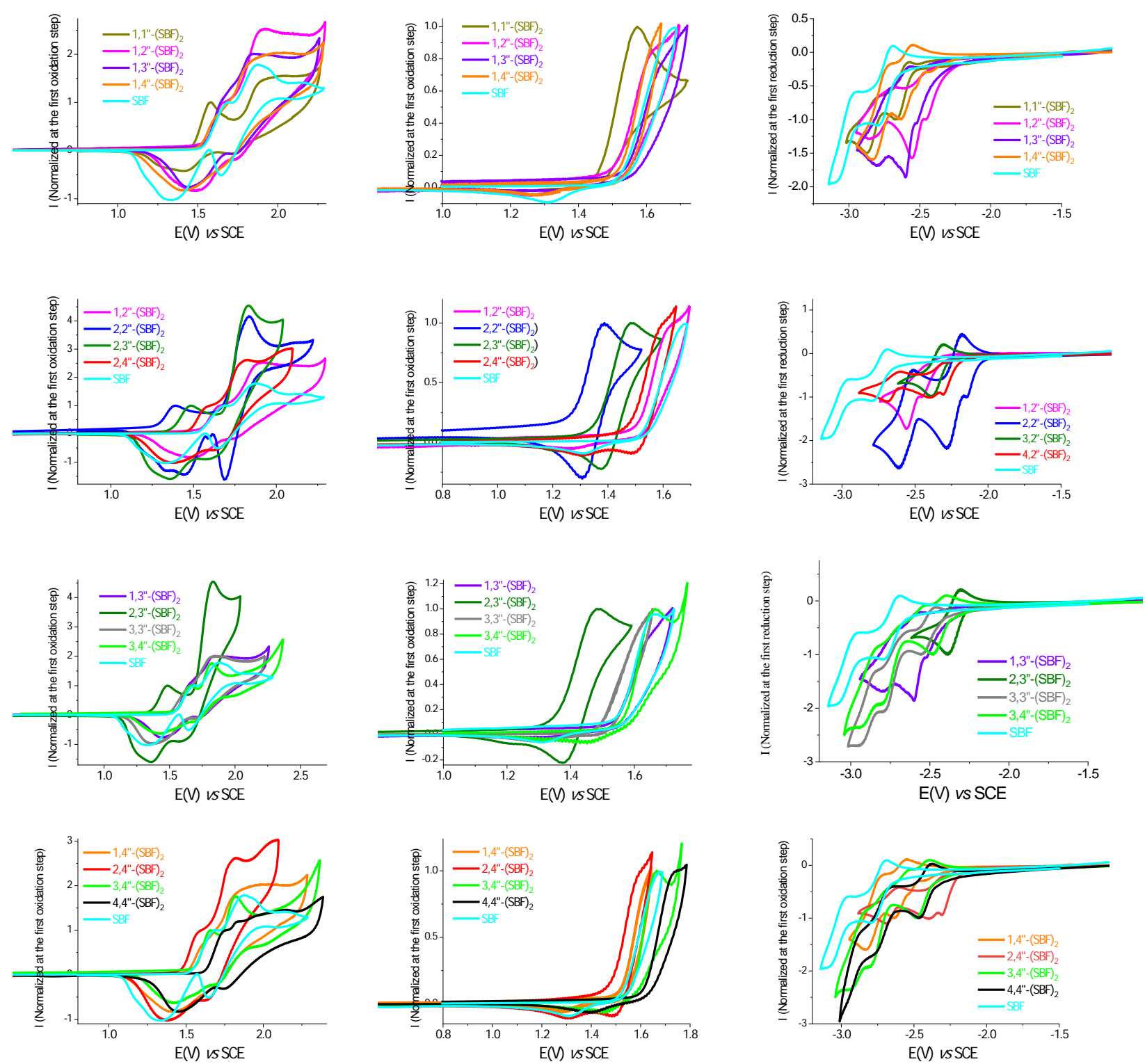

Figure 8. $\mathrm{CV}$ of the ten dimers. Oxidation: $\mathrm{DCM}+\mathrm{Bu}_{4} \mathrm{NPF}_{6} 0.2 \mathrm{M}$, Reduction $\mathrm{DMF}+\mathrm{Bu}_{4} \mathrm{NPF}_{6} 0.2 \mathrm{M}$ From top to bottom: C1-series; C2 series; C3 series and C4 series, $\mathbf{S B F}$ is given as model.

The last important parameter we need to discuss is the frontier molecular orbitals energies. Electrochemistry is a useful tool to evaluate HOMO and LUMO energy levels from the anodic and cathodic explorations. ${ }^{[53]}$ In organic electronics, HOMO/LUMO energy levels are key data as they drive many devices parameters such as the threshold voltage in an OLED. Electrochemical data and corresponding HOMO/LUMO are gathered in Table 1 and Figures 8 and 9. The electrochemical investigations were performed in $\mathrm{Bu}_{4} \mathrm{NPF}_{6} 0.2 \mathrm{M}$ in $\mathrm{CH}_{2} \mathrm{Cl}_{2}$ in oxidation and in $\mathrm{Bu}_{4} \mathrm{NPF}_{6} 0.1 \mathrm{M}$ in DMF in reduction, using a platinum disk as working electrode, a vitreous carbon rod as counter electrode and a reference electrode $\left(\mathrm{Ag} / \mathrm{AgNO}_{3} 0.1 \mathrm{M}\right.$ in $\mathrm{CH}_{3} \mathrm{CN}$ in oxidation in $\mathrm{CH}_{2} \mathrm{Cl}_{2}$ or $\mathrm{Ag} / \mathrm{AgI}$, 
$\mathrm{I}^{-}\left(\mathrm{BU}_{4} \mathrm{NI} 0.1 \mathrm{M}\right)$ in DMF in reduction). For purpose of comparison, all the potentials are referred to SCE (see experimental details in SI).

Let's start, this time, with the C1-series, which has shown the most blue-shifted absorption and emission spectra.

Electrochemical investigations have surprisingly revealed that the first oxidation potential and therefore the HOMO energies were reported almost identical, $-5.95,-5.95$ and $-5.92 \mathrm{eV}$ for 1,2''(SBF)2, 1,3'-(SBF)2 and for 1,4'-(SBF)2 respectively. This shows that the HOMO is only weakly dependent on the substitution pattern, the HOMO of their building block SBF being also measured at $\mathrm{ca}-5.95 \mathrm{eV}$. As all the molecules display a high dihedral angle between the fluorenes, this feature shows the importance of the steric hindrance on the HOMO energy levels.

Indeed, even with the C2-scaffold and its para linkage, the large dihedral angle between the two connected fluorenes fully breaks the conjugation and the resulting HOMO is kept identical to that of SBF. In these systems, the steric hindrance appears as the driving force erasing the effect of the linkage. Surprisingly, 1,1"'-(SBF) 2 with its C1/C1 linkage (dihedral angle of $61.1^{\circ}$ ) displays a different behaviour compared to its regioisomers and its first oxidation wave is shifted to a lower potential $(1.53 \mathrm{~V})$ leading to the highest HOMO $(-5.84 \mathrm{eV})$ in the series. In addition, this wave is bielectronic whereas the first wave of the other isomers was found to be monoelectronic. This has been assigned to the particular structural arrangement of 1,1'”-(SBF)2 which shows $\mathrm{sp}^{2}-\mathrm{CH}$ $\pi$ interactions and $\pi-\pi$ interactions between facing fluorenes as revealed by analysis of the molecular structure by X-Ray crystallography (Figure 2). The two cofacial fluorene dimers are concomitantly oxidised. This is supported by the delocalization of the HOMO, which is spread out on the entire molecule and not only on one SBF as observed for the three other isomers (Figure 5, Right). The singular arrangement of this dimer drastically changes its electrochemical properties.

The cathodic explorations have clearly shown a different behaviour (Figure 8, Right). Indeed, the LUMO energy of 1,2' '-(SBF) 2 is, this time, the lowest of the series $(-2.11 \mathrm{eV})$. As the LUMO of SBF is reported at $-1.74 \mathrm{eV}$, this indicates a certain degree of coupling between the two connected fluorenes in 1,2' '-(SBF)2. This is a drastically different result from what was observed for the HOMO. In this example, the torsion between the two fluorenes seems to have a significantly greater impact on the HOMO energy than on the LUMO energy (that shows the influence of the electronic effect of the para linkage). This experimental result is confirmed by the electronic delocalization of the LUMO obtained by theoretical calculations, which is spread out on the two connected fluorenes (Figure 7, Middle). The important question was now to determine if this holds true for the other dimers families. In this C1 series, the answer is yes. The same effect is indeed observed for 1,3'-(SBF)2 and 1,4'(SBF)2 (LUMO=-2.01 and $-1.90 \mathrm{eV}$ respectively) but appears less pronounced due to the nature of their linkages (meta and ortho respectively vs para for 1,2''-(SBF) 2 ). This is also in accordance with HOMO and LUMO distributions (Figure 7). Due to the particular geometry of 1,1'"-(SBF)2, its LUMO energy level does not follow this trend $(-1.84 \mathrm{eV})$.

These first set of data clearly shows the different impact of the linkage and its torsion on the HOMO/LUMO distribution. Does this behaviour true for the other series of dimers? The answers are presented below.

Let's shift now to the C2-series, which is the less sterically hindered. Oppositely to what was observed above for the C1-series, the HOMO energies were all very different, $-5.95,-5.68,-5.76$ and $-5.88 \mathrm{eV}$ for 1,2"'-(SBF)2, 2,2'’-(SBF)2, 2,3''-(SBF)2 and 2,4''-(SBF)2 respectively. As expected, the highest HOMO is recorded for 2,2''-(SBF)2 with its relaxed para/para linkage. Then, comes 2,3'”-(SBF)2 displaying also a low fluorene/fluorene dihedral angle but a meta/para linkage. The HOMO energy continues to decrease as the dihedral angle increases, 2,4''-(SBF) 2 (42.6 $6^{\circ}$ ) and 1,2' '-(SBF)2, $\left(54.9^{\circ}\right)$. This shows, as observed for the $\mathrm{C} 1$ series (but in a different way as all the angles were very high in this series), the great impact of the steric hindrance on the HOMO energies. The HOMO difference 
between 1,2'-(SBF)2 and 2,4'-(SBF)2 cannot be nevertheless fully assigned to steric considerations as the meta/para linkage of the former (vs para/ortho linkage for the latter) can also be involved in its lower HOMO. In these examples, the effect of the dihedral angle on the HOMO energy is clear, the higher the angle, the lower the HOMO.

The cathodic explorations of this series confirm the different impact of the linkage and torsion effects on the HOMO and LUMO distribution. Thus, the LUMO energies of 1,2''-(SBF)2, 2,2'-(SBF)2, 2,3' -(SBF)2 and 2,4' '-(SBF)2 were respectively reported at -2.11, -2.34, -2.14 and -2.22 eV. In these examples, the decrease of the LUMO (LUMO of SBF is $-1.74 \mathrm{eV}$ ) is twice larger in magnitude compared to the increase of the HOMO observed above, showing the importance of the linkage on the LUMO energy levels. The LUMO energy levels of the C2 series follows a trend driven by the nature of the linkage: the two highest being the C1 and C3 meta linkages, followed by the C4 ortho linkage and finally the C2 para linkage. Comparison of 2,3'-(SBF) 2 and 2,4'-(SBF) 2 are particularly relevant to illustrate this feature. Indeed, 2,4'-(SBF)2 possesses a lower LUMO than $\mathbf{2 , 3}$ '”-(SBF) (due to different linkage ortho vs meta) but also a lower HOMO (due to the higher fluorene/fluorene dihedral angle). This shows that the steric congestion between the fluorenes mainly drives the HOMO whereas the electronic nature of the linkages mainly drives the LUMO. This will be confirmed below in the C3 series with 3,3'’-(SBF)2 and 3,4'”-(SBF)2.

The C3-series is characterized by its meta linkage, which, in principle, strongly disturbs the $\pi$ electronic delocalization. ${ }^{[4,45]}$ This linkage also leads to a different impact on the HOMO and LUMO energies. The HOMO energies were measured at $-5.95,-5.76,-5.90$ and $-5.97 \mathrm{eV}$ for 1,3''-(SBF)2, 2,3'-(SBF)2, 3,3''-(SBF)2 and 3,4'-(SBF)2 respectively. As for the C2 series, we can split this family into two groups: those construct on relaxed platforms (C2 and C3), i.e. 2,3'"-(SBF)2 and 3,3'”(SBF) 2 and those constructed on encumbered platforms (C1 and C4), i.e. 1,3'-(SBF)2 and 3,4'”(SBF)2. Thus, the highest HOMO is obviously recorded for 2,3"-(SBF)2 with its relaxed para/meta linkage and low dihedral angle $\left(40.0^{\circ}\right)$ followed by 3,3"-(SBF) 2 with its meta/meta linkage and a low dihedral angle $\left(37.3^{\circ}\right)$. The HOMO energy of the two other isomers $\mathbf{1 , 3}$ ”-(SBF)2 and 3,4"-(SBF) 2 constructed on encumbered platforms are the lowest in this series and close to that of SBF, indicating a very weak conjugation between the fluorene units. As the dihedral angle increases, the HOMO decreases.

A last feature should be precise. Except for 2,2"-(SBF)2 and 2,3"-(SBF)2, the anodic explorations show, for each dimer, an irreversible first oxidation process. The irreversibility of the oxidation signs the high reactivity of the radical cations formed at the first oxidation process. The radical-cations are involved in carbon-carbon couplings leading to electrodeposition (see new reduction waves at the reverse scan for all the dimers in the first column of Figure 8). These electrodeposition processes due to the insolubility of the oligomers formed upon the couplings are classically observed for fluorene, ${ }^{[54]}$ extended fluorenes, ${ }^{[55,56]}$ SBF $^{[57]}$ and many electroactive materials based on SBF ${ }^{[25,26,58-60]}$ For 2,2"(SBF) 2 and 2,3"-(SBF)2, the electrodeposition process occurs at the second oxidation step due to the higher stability of the corresponding radical-cations due to the conjugation extension.'

In reduction, the behaviour is different and driven by the linkage. The lowest LUMO are recorded for 2,3"-(SBF) $2(-2.14 \mathrm{eV})$ and for 3,4'’-(SBF) $2(-2.05 \mathrm{eV})$, possessing respectively a para and an ortho linkage, which in principle extends the $\pi$-delocalization. The two other dimers have higher LUMO due to the meta linkage (-2.01 and $-1.98 \mathrm{eV}$ for $\mathbf{1 , 3}$ ”-(SBF)2 and 3,3”-(SBF)2 respectively). This trend is identical to that highlighted above for the C2 series. The comparison of HOMO/LUMO energy levels of 3,3'"-(SBF) 2 and 3,4''-(SBF) 2 appears particularly relevant to confirm the laws exposed above for the C2-series. Thus, the HOMO/LUMO energies of 3,4''-(SBF) $)_{2}(-5.97 /-2.05 \mathrm{eV})$ are both lower than those of 3,3' '-(SBF) 2 (-5.90/-1.98 eV) confirming that the dihedral angle drives the energy of the HOMO whereas the electronic nature of the linkage drives that of the LUMO. To conclude, the two relaxed C2 and C3 platforms display the same trend and obeys the same rules. 
Finally, in the C4-series, as in the C1-series, all the dihedral angles are high and therefore all the HOMO are deep and almost identical to that of SBF: -5.92, -5.88, -5.97 and -6.01 eV for 1,4'-(SBF)2, 2,4''-(SBF)2, 3,4'”-(SBF)2 and 4,4''-(SBF)2 respectively. Subtle nuances should nevertheless be stated.

First, one can note that the HOMO of 2,4' '-(SBF) 2 is higher than the others. This is different to what was observed with its C1 analogue, 1,2''-(SBF)2 exposed above (the HOMO of 1,2'-(SBF) 2 was identical to that of SBF), and in accordance with the lower dihedral angle measured for 2,4''-(SBF)2 vs 1,2'-(SBF)2 (42.6 vs 54.9', in this case the linkage can also be involved). Thus, in the case of 2,4'-(SBF)2, despite a rather high dihedral angle, the conjugation is not completely broken and the HOMO energy is modified. This result appears particularly interesting as it shows how, even with a sterically hindered platform, a fine tuning of the HOMO level can be performed. For the three other dimers 1,4'-(SBF)2, 3,4'-(SBF)2 and 4,4''-(SBF)2, the HOMO is very deep and even lower than that of SBF for the two latters. These three dimers display the highest dihedral angles in the series (76.9, 58.9 and $88.3^{\circ}$ respectively, Figure 2 ) and it can be hypothesized that some deformations of the fluorene units may occur leading to a perturbation of the conjugation (as previously observed for other structurally related compounds). ${ }^{[31]}$ The lowest HOMO is reported for the dimer displaying the highest dihedral angle, 4,4”'(SBF)2.

The LUMO energies of the C4 series were measured at -1.90, -2.22, -2.05 and -2.06 eV for 1,4'”(SBF)2, 2,4'-(SBF)2, 3,4'-(SBF)2 and 4,4'-(SBF)2 respectively. As observed for the other series, the SBF dimerization has a stronger influence on the LUMO than on the HOMO. The meta linkages of 1,4'-(SBF)2 and 3,4'-(SBF)2 provide the highest LUMO, whereas the ortho linkage of 4,4'(SBF)2 and more importantly the para linkage of 2,4''-(SBF)2 provide the lowest LUMO.

Thus, in the C4 series, the C2 isomer, 2,4"'-(SBF)2 displays the highest HOMO and lowest LUMO. This behaviour is identical to that of C2 and C3 series (2,2'”-(SBF)2 and 2,3'"-(SBF) 2 also display the highest HOMO and lowest LUMO) but different than that of the C1 series (1,2'’-(SBF)2 display the lowest LUMO but not the highest HOMO). This translates the different impact of the steric congestion between the fluorenes and the resulting different HOMOs evolution, the C4 platform providing, in this example, less steric constraints than the C1 platform (in accordance with the dihedral angles). However, the three other dimers, 1,4'-(SBF)2, 3,4"'-(SBF)2 and 4,4"'-(SBF)2 display a very high dihedral angle and hence the lowest HOMO in all the dimers studied. Their LUMO are nevertheless significantly lower than that of SBF, confirming the rules exposed above on the parameters influencing the HOMO and LUMO evolution.

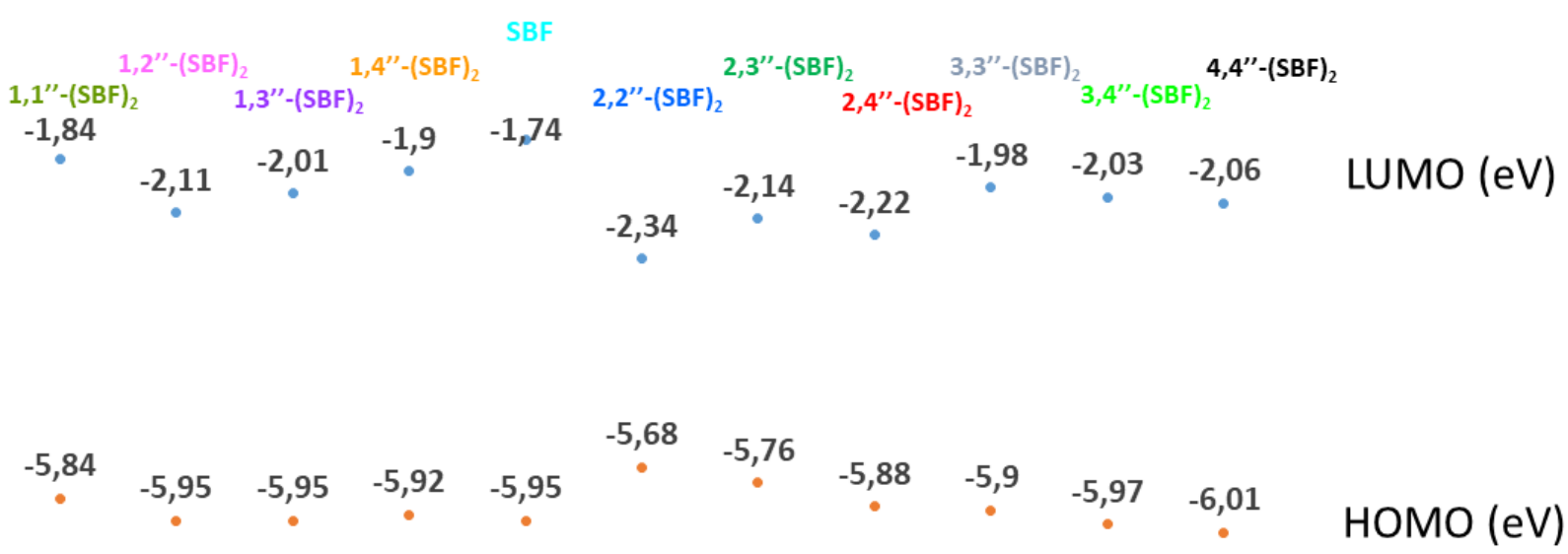

Figure 9. HOMO/LUMO energy levels obtained from cyclic voltammetries. 
These electrochemical investigations show that these regioisomers are driven by the same laws. The nature of the fluorene/fluorene linkage and the dihedral angle between these units drive the $\pi$ electrons delocalization. The impact of these two parameters is not only different as a function of the isomer considered but also as a function of the frontier molecular orbital considered, ie HOMO (benzenoidal) or LUMO (quinoidal). Thus, the torsion (steric effect) between two connected fluorenes seems to always have a greater impact on the HOMO energy than on the LUMO energy, the latter being more sensitive to the electronic effect of the linkage. This feature provides a remarkable way to selectively tune their energies.

Table 1. Selected Properties of the ten dimers and SBF.

\begin{tabular}{|c|c|c|c|c|c|c|c|c|c|c|c|}
\hline & $\begin{array}{c}1,1 ’ '- \\
(\mathrm{SBF})_{2}\end{array}$ & $\begin{array}{c}1,2 ’ ’ \\
(\mathrm{SBF})_{2}\end{array}$ & $\begin{array}{c}1,3 ’- \\
(S B F) \\
2 \\
\end{array}$ & \begin{tabular}{|c}
1,4 '”- \\
(SBF) \\
2 \\
\end{tabular} & $\begin{array}{c}\mathbf{S B F}^{[16,24,} \\
\text {, }\end{array}$ & $\begin{array}{l}2,2, '- \\
(\mathrm{SBF})_{2}\end{array}$ & $\begin{array}{l}2,3 ’ ’ \\
(\mathrm{SBF})_{2}\end{array}$ & $\begin{array}{l}2,4 ’ ’ \\
(\mathrm{SBF})_{2}\end{array}$ & $\begin{array}{l}3,3 ’- \\
(\mathrm{SBF})_{2}\end{array}$ & $\begin{array}{l}3,4 ’- \\
(\mathrm{SBF})_{2}\end{array}$ & $\begin{array}{r}4,4 ’ \cdot- \\
(\mathrm{SBF})_{2}\end{array}$ \\
\hline $\begin{array}{l}\text { Dihedral angle } \\
\text { between the two } \\
\text { fluorene (from X- } \\
\text { Ray) }\end{array}$ & 61.1 & 54.9 & 57.9 & 76.9 & - & 0.0 & 40.0 & 42.6 & 37.3 & 58.9 & 88.3 \\
\hline $\begin{array}{l}\text { Dihedral angle in } \\
\text { S1 state (from } \\
\text { theoretical } \\
\text { calculations) } \\
\end{array}$ & 61.2 & 40.9 & 51.5 & 42.6 & - & 10.1 & 10.0 & 31.9 & 4.0 & 29.8 & 89.7 \\
\hline $\begin{array}{l}\text { Dihedral angle in } \\
\text { T1 state (from } \\
\text { theoretical } \\
\text { calculations) }\end{array}$ & 62.6 & 47.2 & 71.1 & 75.7 & - & 0.0 & 0.0 & 31.0 & 0.0 & 30.1 & 44.1 \\
\hline $\begin{array}{l}\lambda_{\text {abs }}[\mathrm{nm}] \\
\left(\times 10^{4} \mathrm{~L} \cdot \mathrm{mol}^{-1} \cdot \mathrm{cm}^{-}\right. \\
1)^{\mathrm{a}}\end{array}$ & 312 & $\begin{array}{c}310 \\
316(\mathrm{sh})\end{array}$ & 310 & 310 & 308 & $\begin{array}{l}309 \\
329\end{array}$ & $\begin{array}{c}309 \\
321(\mathrm{sh})\end{array}$ & $\begin{array}{c}309 \\
318(\mathrm{sh})\end{array}$ & $\begin{array}{l}309 \\
318\end{array}$ & 309 & 309 \\
\hline$\lambda_{\text {fluo }}(\mathrm{nm})^{\mathrm{a}}$ & $325^{\mathrm{a}}$ & $335^{\mathrm{a}}$ & $320^{\mathrm{a}}$ & $326^{\mathrm{a}}$ & $\begin{array}{l}310 \\
323\end{array}$ & $\begin{array}{l}360 \\
380 \\
401\end{array}$ & $\begin{array}{l}347 \\
362 \\
380\end{array}$ & 377 & $\begin{array}{l}342 \\
355 \\
372\end{array}$ & 365 & 365 \\
\hline$\lambda_{\text {phospho }}(\mathrm{nm})^{\mathrm{b}}$ & 435 & 443 & 432 & 434 & 429 & 526 & 491 & 470 & 436 & 454 & 438 \\
\hline$\lambda_{\text {abs }}-\lambda_{\text {fluo }}(\mathrm{nm})$ & 13 & 18 & 11.5 & 16.5 & 2 & 30 & 25 & 59 & 24 & 56 & 56 \\
\hline $\mathrm{QY}^{\mathrm{c}}$ & 0.25 & 0.77 & 0.47 & 0.37 & 0.55 & 0.99 & 0.89 & 0.80 & 0.59 & 0.51 & 0.33 \\
\hline$\tau_{\mathrm{f}}[\mathrm{ns}]$ & 4.6 & 2.0 & 4.4 & 4.2 & 4.6 & 0.9 & 1.5 & 2.1 & $\begin{array}{c}4.0 \\
(71 \%) \\
7.8 \\
(29 \%)^{\mathrm{h}} \\
\end{array}$ & 2.8 & 2.8 \\
\hline $\mathrm{k}_{\mathrm{r}}\left(\times 10^{7}\right)\left[\mathrm{s}^{-1}\right]$ & 5.4 & 39 & 11 & 8.8 & 12 & 110 & 59 & 38 & 15 & 18 & 12 \\
\hline $\mathrm{k}_{\mathrm{nr}}\left(\times 10^{7}\right)\left[\mathrm{s}^{-1}\right]$ & 16 & 12 & 12 & 15 & 10 & 1.1 & 7.3 & 9.5 & $10^{\mathrm{i}}$ & 19 & 24 \\
\hline$\tau_{\mathrm{p}}[\mathrm{s}]$ & 5.1 & 4.8 & 5.6 & 5.7 & 5.4 & 1.3 & 3.2 & 3.9 & 4.4 & 3.9 & 5.1 \\
\hline LUMO $(\mathrm{eV})^{\mathrm{d}}$ & -1.84 & -2.11 & -2.01 & -1.90 & -1.74 & -2.34 & -2.14 & -2.22 & -1.98 & -2.05 & -2.06 \\
\hline LUMO th $(\mathrm{eV})$ & -1.37 & -1.40 & -1.34 & -1.37 & -1.26 & -1.66 & -1.53 & -1.54 & -1.35 & -1.38 & -1.29 \\
\hline $\operatorname{HOMO}(\mathrm{eV})^{\mathrm{e}}$ & -5.84 & -5.95 & -5.95 & -5.92 & -5.95 & -5.68 & -5.76 & -5.88 & -5.90 & -5.97 & -6.01 \\
\hline HOMO th $(\mathrm{eV})$ & -5.86 & -5.89 & -5.90 & -5.87 & -5.99 & -5.67 & -5.76 & -5.87 & -5.84 & -5.95 & -6.00 \\
\hline \begin{tabular}{l|l}
$\Delta \mathrm{E}$ & $\mathrm{Opt}^{\mathrm{f}}$ \\
\end{tabular} & 3.89 & 3.84 & 3.92 & 3.94 & 3.97 & 3.45 & 3.61 & 3.68 & 3.76 & 3.85 & 3.94 \\
\hline $\begin{array}{ll} & \mathrm{El}^{\mathrm{g}} \\
\end{array}$ & 4.00 & 3.84 & 3.94 & 4.02 & 4.21 & 3.34 & 3.62 & 3.66 & 3.92 & 3.94 & 3.95 \\
\hline $\mathrm{E}_{\mathrm{T}}(\mathrm{eV})^{\mathrm{b}}$ & 2.85 & 2.80 & 2.87 & 2.86 & 2.89 & 2.36 & 2.53 & 2.64 & 2.84 & 2.73 & 2.83 \\
\hline $\mathrm{E}_{\mathrm{S}}(\mathrm{eV})^{\mathrm{i}}$ & 4.01 & 3.96 & 4.03 & 4.03 & 4.05 & 3.54 & 3.70 & 3.66 & 3.76 & 3.79 & 3.79 \\
\hline
\end{tabular}

sh = shoulder a. in cyclohexane, b. from the first maximum of the emission spectra at $77 \mathrm{~K}$ in 2-Me-THF, c. compare to quinine sulfate, d. from CVs in DCM, e. from CVs in DMF, f. from UV-Vis spectra in cyclohexane, g. LUMO (DMF) - HOMO (DCM); h. for $\tau_{f}=4$ ns, i. from the onset of the fluorescence spectrum at room temperature.

\section{Conclusion}


In the present work, we unravel the impact of the two main parameters involved in the electrochemical and photophysical properties of SBF dimers, namely the nature of the phenyl linkages and the steric congestion. We show how the combination of these two parameters finely tunes the electronic properties of the SBF dimers and how their respective weights are different as a function of the regioisomer involved and of the property considered (HOMO or LUMO energy level, absorption, fluorescence, phosphorescence). This is particularly important to control all the electronic properties to accurately design efficient functional materials for a specified application. As the new generations of SBF isomers have only been reported in the last five years, these design guidelines may contribute to develop this fragment. Finally, it should be mentioned that new generations of double linked dimers have recently been reported in literature (Figure 10). ${ }^{[62]}$ In these structures, the two fluorenes are attached by their $\mathrm{C} 2 / \mathrm{C} 2$ ' positions and benzene rings appear to be strongly bent as in nanorings. ${ }^{[63,64]}$ In these dimers, the size of the cavity and more importantly the electronic properties can be strongly modulated by modifying these anchor points following the guidelines provided in this work. For example, a substitution at $\mathrm{C} 1 / \mathrm{C} 1$ ' positions will provide a very high $\mathrm{E}_{\mathrm{T}}$ material and a small cavity. In any event, we are convinced that SBF dimers and more generally the SBF fragment will remain a central scaffold in the future of organic electronics.
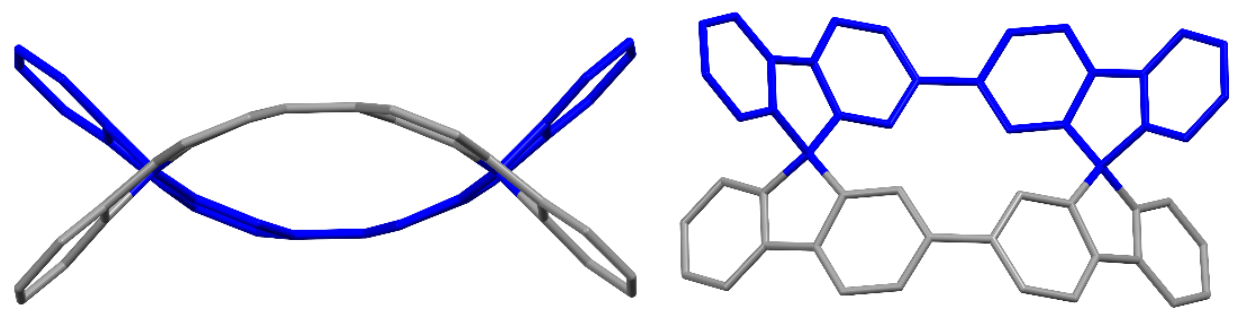

Figure 10. Example of a double-linked dimer reported by Amaya and coworkers. ${ }^{[62]}$

\section{Acknowledgments}

The authors thank all the collaborators, which have been involved in the SBF dimers project. Dr L. Sicard (Rennes) is especially acknowledged for pioneering works on the 1-SBF dimers. Dr O. Jeannin (Rennes) is particularly acknowledged for crystallography. We also thank Dr O. Galangau and Dr L. Favereau (Rennes) for their help in spectroscopy. We wish to thank the CINES under the allocation 2021-A0100805032 made by GENCI (Montpellier), the ANR (SPIROQUEST N¹9-CE05-024), the Région Bretagne (DIADEM) for PhD grant (FL). The authors thank Dr J. F. Bergamini (Rennes) for the TOC material.

Supporting Information Available: Synthetic, X-ray and theoretical calculations details. This material is available free of charge via the Internet at http://pubs.acs.org

\section{References}

[1]R. G. Clarkson, M. Gomberg, J. Am. Chem. Soc. 1930, 52, 2881-2891.

[2]C. Poriel, L. Sicard, J. Rault-Berthelot, Chem. Comm. 2019, 55, 14238-14254.

[3]Z.-Q. Jiang, C. Poriel, N. Leclerc, Mater. Chem. Front. 2020, 4, 2497-2498.

[4]T. P. I. Saragi, T. Spehr, A. Siebert, T. Fuhrmann-Lieker, J. Salbeck, Chem. Rev. 2007, 107, 10111065.

[5]C. Poriel, J. Rault-Berthelot, J. Mater. Chem. C 2017, 5, 3869-3897 
[6]E. Demers, T. Maris, J. Cabana, J.-H. Fournier, J. D. Wuest, Cryst. Growth Des. 2005, 5, 12371245.

[7]J.-H. Fournier, T. Maris, J. D. Wuest, J. Org. Chem. 2004, 69, 1762-1775.

[8]F. Moreau, N. Audebrand, C. Poriel, V. Moizan-Baslé, J. Ouvry, J. Mater. Chem. 2011, 21, 18715-18722.

[9]F. Moreau, N. Audebrand, C. Poriel, CrystEngComm 2020, 22, 293-303.

[10]H.-D. Guo, X. M. Guo, S. R. Batten, J.-F. Song, S.-Y. Song, S. Dang, G.-L. Zheng, J.-K. Tang, H.-J. Zhang, Cryst. Growth Des. 2009, 9, 1394-1401.

[11]T. A. Schaub, E. A. Prantl, J. Kohn, M. Bursch, C. R. Marshall, E. J. Leonhardt, T. C. Lovell, L. N. Zakharov, C. K. Brozek, S. R. Waldvogel, S. Grimme, R. Jasti, J. Am. Chem. Soc. 2020, 142, 8763-8775.

[12]K. Ding, Z. Han, Z. Wang, Chem. Asian. J. 2009, 4, 32-41.

[13]V. Alcazar, F. Diederich, Angew. Chem. Int. Ed. 1992, 31, 1521-1523.

[14]K. Zhu, K. Kamochi, T. Kodama, M. Tobisu, T. Amaya, Chem. Sci. 2020, 11, 9604-9610.

[15]X. Cheng, Q. Zhang, J.-H. Xie, L.-X. Wang, Q.-L. Zhou, Angew. Chem. Int. Ed. 2005, 44, 11181121.

[16]L. Sicard, C. Quinton, J.-D. Peltier, D. Tondelier, B. Geffroy, U. Biapo, R. Métivier, O. Jeannin, J. Rault-Berthelot, C. Poriel, Chem. Eur. J. 2017, 23, 7719-7723.

[17]J. Jalkh, S. Thiery, J.-F. Bergamini, P. Hapiot, C. Poriel, Y. R. Leroux, J. Phys. Chem. C 2017, $121,14228-14237$.

[18]H. Lee, H. Jung, S. Kang, J. H. Heo, S. H. Im, J. Park, J. Org. Chem. 2018, 83, 2640-2646.

[19]D. Xia, D. Gehrig, X. Guo, M. Baumgarten, F. Laquai, K. Mullen, J. Mater. Chem. A 2015, 3, 11086-11092.

[20]D. Xia, X. Guo, M. Wagner, M. Baumgarten, D. Schollmeyer, K. Müllen, Crystal Growth \& Design 2017, 17, 2816-2821.

[21]I. Pyka, J. Nikl, D. Schollmeyer, S. R. Waldvogel, Eur. J. Org. Chem. 2017, 2017, 3501-3504.

[22]L. Sicard, C. Quinton, F. Lucas, O. Jeannin, J. Rault-Berthelot, C. Poriel, J. Phys. Chem. C 2019, 123, 19094-19104.

[23]L.-S. Cui, S.-C. Dong, Y. Liu, M.-F. Xu, Q. Li, Z.-Q. Jiang, L.-S. Liao, Org. Electron. 2013, 14, 1924-1930.

[24]Q. Wang, F. Lucas, C. Quinton, Y.-K. Qu, J. Rault-Berthelot, O. Jeannin, S.-Y. Yang, F.-C. Kong, S. Kumar, L.-S. Liao, C. Poriel, Z.-Q. Jiang, Chem. Sci. 2020, 11, 4887-4894.

[25]S. Thiery, C. Declairieux, D. Tondelier, G. Seo, B. Geffroy, O. Jeannin, R. Métivier, J. RaultBerthelot, C. Poriel, Tetrahedron 2014, 70, 6337-6351.

[26]C. Quinton, S. Thiery, O. Jeannin, D. Tondelier, B. Geffroy, E. Jacques, J. Rault-Berthelot, C. Poriel, ACS Appl. Mater. Interfaces. 2017, 9, 6194-6206.

[27]L.-S. Cui, Y.-M. Xie, Y.-K. Wang, C. Zhong, Y.-L. Deng, X.-Y. Liu, Z.-Q. Jiang, L.-S. Liao, Adv. Mater. 2015, 27, 4213-4217.

[28]J.-J. Liang, Y. Li, Y. Yuan, S.-H. Li, X.-D. Zhu, S. Barlow, M.-K. Fung, Z.-Q. Jiang, S. R. Marder, L.-S. Liao, Mater. Chem. Front. 2018, 2, 917-922.

[29]L. J. Sicard, H.-C. Li, Q. Wang, X.-Y. Liu, O. Jeannin, J. Rault-Berthelot, L.-S. Liao, Z.-Q. Jiang, C. Poriel, Angew. Chem. Int. Ed. 2019, 58, 3848-3853.

[30]Y. Che, D. F. Perepichka, Angew. Chem. Int. Ed. 2021, 60, 1364-1373.

[31]C. Poriel, J. Rault - Berthelot, Acc. Chem. Res. 2018, 51, 1818-1830.

[32]J.-D. Peltier, B. Heinrich, B. Donnio, O. Jeannin, J. Rault-Berthelot, E. Jacques, C. Poriel, J. Mater. Chem. C 2018, 6, 13197-13210.

[33]S. Bebiche, P. Cisneros-Perez, T. Mohammed-Brahim, M. Harnois, J. Rault - Berthelot, C. Poriel, E. Jacques, Mater. Chem. Front. 2018, 2, 1631-1641.

[34]J.-D. Peltier, B. Heinrich, B. Donnio, E. Jacques, J. Rault-Berthelot, C. Poriel, ACS Appl. Mater. Interfaces 2017, 9, 8219-8232. 
[35]M. Romain, C. Quinton, D. Tondelier, B. Geffroy, O. Jeannin, J. Rault-Berthelot, C. Poriel, J. Mater. Chem. C 2016, 4, 1692-1703.

[36]T.-C. Chao, y.-T. Lin, C. Y. Yang, C.-H. Hung, H.-C. Chou, C.-C. Wu, K.-T. Wong, Adv. Mater. 2005, 992-996.

[37]K.-T. Wong, Y.-L. Liao, Y.-T. Lin, H.-C. Su, C.-C. Wu, Org. Lett. 2005, 7, 5131-5134.

[38]Z. Jiang, H. Yao, Z. Zhang, C. Yang, Z. Liu, Y. Tao, J. Qin, D. Ma, Org. Lett. 2009, 11, 26072610.

[39]S. Liu, D. Xia, M. Baumgarten, ChemPlusChem 2021, 21, 36-48.

[40]C.-J. Ou, C. Zhu, X.-H. Ding, L. Yang, J.-Y. Lin, L.-H. Xie, Y. Qian, C.-X. Xu, J.-F. Zhao, W. Huang, J. Mater. Chem. C 2017, 5, 5345-5355.

[41]A. Nangia, Acc. Chem. Res. 2008, 41, 595-604.

[42]X. Tang, L.-S. Cui, H.-C. Li, A. J. Gillett, F. Auras, Y.-K. Qu, C. Zhong, S. T. E. Jones, Z.-Q. Jiang, R. H. Friend, L.-S. Liao, Nat. Mater. 2020, 19, 1232-1238.

[43]C. C. Peng, S. Y. Yang, H. C. Li, G. H. Xie, L. S. Cui, S. N. Zou, C. Poriel, Z. Q. Jiang, L. S. Liao, Adv. Mater. 2020, 32, 2003885.

[44]A. Pogantsch, A. K. Mahler, G. Hayn, R. Saf, F. Stelzer, E. J. W. List, J. L. Brédas, E. Zojer, Chem. Phys. 2004, 297, 143-151.

[45]P. Guiglion, M. A. Zwijnenburg, Phys. Chem. Chem. Phys. 2015, 17, 17854-17863.

[46]S. Thiery, B. Heinrich, B. Donnio, C. Poriel, F. Camerel, J. Mater. Chem. C 2014, 2, 4265-4275.

[47]S. Thiery, D. Tondelier, C. Declairieux, B. Geffroy, O. Jeannin, R. Métivier, J. Rault-Berthelot, C. Poriel, J. Phys. Chem. C 2015, 119, 5790-5805.

[48]M. Romain, S. Thiery, A. Shirinskaya, C. Declairieux, D. Tondelier, B. Geffroy, O. Jeannin, J. Rault-Berthelot, R. Métivier, C. Poriel, Angew. Chem. Int. Ed. 2015, 54, 1176-1180.

[49]S. Karaburnaliev, M. Baumgarten, N. Tyutyulkov, K. Müllen, J. Phys. Chem. 1994, 98, 1189211901.

[50]N. Fomina, S. E. Bradforth, T. E. Hogen-Esch, Macromolecules 2009, 42, 6440-6447.

[51]D. Geuenich, K. Hess, F. Köhler, R. Herges, Chem. Rev. 2005, 105, 3758-3772.

[52]G. Heimel, M. Daghofer, J. Gierschner, E. J. W. List, A. C. Grimsdale, K. Müllen, D. Beljonne, J. L. Brédas, E. Zojer, J. Chem. Phys. 2005, 122, 054501-054511.

[53]C. M. Cardona, W. Li, A. E. Kaifer, D. Stockdale, G. C. Bazan, Adv. Mater. 2011, 23, 23672371.

[54]J. Rault-Berthelot, M.-A. Orliac, J. Simonet, Electrochim. Acta 1988, 33, 811-823.

[55]J. Rault-Berthelot, C. Poriel, F. Justaud, F. Barrière, New J. Chem. 2008, 32, 1259-1266.

[56]N. Cocherel, C. Poriel, O. Jeannin, A. Yassin, J. Rault-Berthelot, Dyes Pigm. 2009, 83, 339-347.

[57]J. Rault-Berthelot, M.-M. Granger, L. Mattiello, Synth. Met. 1998, 97, 211-215.

[58]C. Poriel, Y. Ferrand, P. Le Maux, J. Rault-Berthelot, G. Simonneaux, Inorg. Chem. 2004, 43, 5086-5095.

[59]C. Poriel, Y. Ferrand, P. Le Maux, C. Paul-Roth, G. Simonneaux, J. Rault-Berthelot, J. Electroanal. Chem. 2005, 583, 92-103.

[60]C. Poriel, Y. Ferrand, P. Le Maux, J. Rault-Berthelot, G. Simonneaux, Synth. Met. 2008, 158, 796-801.

[61]S. Thiery, D. Tondelier, C. Declairieux, G. Seo, B. Geffroy, O. Jeannin, J. Rault-Berthelot, R. Métivier, C. Poriel, J. Mater. Chem. C 2014, 2, 4156-4166.

[62]J. Oniki, T. Moriuchi, K. Kamochi, M. Tobisu, T. Amaya, J. Am. Chem. Soc. 2019, 141, 1823818245.

[63]L. Sicard, O. Jeannin, J. Rault-Berthelot, C. Quinton, C. Poriel, ChemPlusChem 2018, 83, 874880.

[64]L. Sicard, F. Lucas, O. Jeannin, P. A. Bouit, J. Rault-Berthelot, C. Quinton, C. Poriel, Angew; Chem. Int. Ed. 2020, 59, 11066-11072. 